SAND2001-0193

Unlimited Release

Printed February 2001

\title{
The Embudito Mission: A Case Study of the Systematics of Autonomous Ground Mobile Robots
}

\author{
Patrick J. Eicker \\ Prepared by \\ Sandia National Laboratories \\ Albuquerque, New Mexico 87185 and Livermore, California 94550 \\ Sandia is a multiprogram laboratory operated by Sandia Corporation, \\ a Lockheed Martin Company, for the United States Department of \\ Energy under Contract DE-AC04-94AL85000.
}

Approved for public release; further dissemination unlimited.

\section{in Sandia National Laboratories}




\section{Issued by Sandia National Laboratories, operated for the United States Department of Energy by Sandia Corporation.}

NOTICE: This report was prepared as an account of work sponsored by an agency of the United States Government. Neither the United States Government, nor any agency thereof, nor any of their employees, nor any of their contractors, subcontractors, or their employees, make any warranty, express or implied, or assume any legal liability or responsibility for the accuracy, completeness, or usefulness of any information, apparatus, product, or process disclosed, or represent that its use would not infringe privately owned rights. Reference herein to any specific commercial product, process, or service by trade name, trademark, manufacturer, or otherwise, does not necessarily constitute or imply its endorsement, recommendation, or favoring by the United States Government, any agency thereof, or any of their contractors or subcontractors. The views and opinions expressed herein do not necessarily state or reflect those of the United States Government, any agency thereof, or any of their contractors.

Printed in the United States of America. This report has been reproduced directly from the best available copy.

Available to DOE and DOE contractors from

U.S. Department of Energy

Office of Scientific and Technical Information

P.O. Box 62

Oak Ridge, TN 37831

Telephone: (865)576-8401

Facsimile: (865)576-5728

E-Mail: reports@adonis.osti.gov

Online ordering: http://www.doe.gov/bridge

Available to the public from

U.S. Department of Commerce

National Technical Information Service

5285 Port Royal Rd

Springfield, VA 22161

Telephone: (800)553-6847

Facsimile: (703)605-6900

E-Mail: orders@ntis.fedworld.gov

Online order: http://www.ntis.gov/ordering.htm

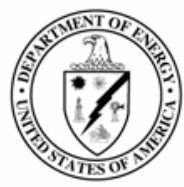


SAND2001-0193

Unlimited Release

Printed February 2001

\title{
The Embudito Mission: \\ A Case Study of the Systematics of Autonomous Ground Mobile Robots
}

\author{
Patrick J. Eicker \\ Intelligent Systems and Robotics Center \\ Sandia National Laboratories \\ P. O. Box 5800 \\ Albuquerque, NM 87185-1002
}

\begin{abstract}
Ground mobile robots are much in the mind of defense planners at this time, being considered for a significant variety of missions with a diversity ranging from logistics supply to reconnaissance and surveillance. While there has been a very large amount of basic research funded in the last quarter century devoted to mobile robots and their supporting component technologies, little of this science base has been fully developed and deployed - notable exceptions being NASA's Mars rover and several terrestrial derivatives. The material in this paper was developed as a first exemplary step in the development of a more systematic approach to the R\&D of ground mobile robots.
\end{abstract}




\section{Contents}

$\begin{array}{ll}\text { Introduction } & 7\end{array}$

The Mobile Robot as a System $\quad 8$

Overview of this Paper $\quad 8$

The Embudito Reconnaissance and Surveillance Mission 9

Vegetation and Obstacles: The Robot's World on a Twenty

Terrain and Vegetation Density: The Robot's World on a
Thousand Foot Scale

Requirements at the Scale of the Mission Itself 20

$\begin{array}{ll}\text { Robot Communication } & 20\end{array}$

Robot Navigation $\quad 21$

Classification of Vegetation Zones $\quad 23$

Mission Route Planning $\quad 24$

$\begin{array}{ll}\text { Robot Mobility } & 26\end{array}$

The Virtual Robot and the Virtual World $\quad 27$

$\begin{array}{ll}\text { Summary } & 29\end{array}$

Conclusion $\quad 30$ 


\title{
The Embudito Mission A Case Study of the Systematics of Autonomous Ground Mobile Robots
}

\author{
Patrick J. Eicker \\ Sandia National Laboratories
}

\section{Introduction}

Ground mobile robots are much in the mind of defense planners at this time, being considered for a significant variety of missions with a diversity ranging from logistics supply to reconnaissance and surveillance. While there has been a very large amount of basic research funded in the last quarter century devoted to mobile robots and their supporting component technologies, little of this science base has been fully developed and deployed - notable exceptions being NASA's Mars rover and several terrestrial derivatives. Unfortunately, defense planners do not have in hand the type of information contained in the notional Figure 1, and are therefore limited in their ability to make decisions about missions with the highest payoff in the near and long term. Given the expectations of military planners, it is incumbent upon robotic technologists to design a systematic approach which will integrate the requirements for the variety of missions with the readiness status of the varied component technologies, and to then develop a R\&D plan for the necessary science and technology. By using a very specific example as a case study, this paper's intent is to begin a dialog on the development of such systematic approaches. Even more specifically, we primarily focus on issues related to the autonomous navigation and driving of mobile robots, a capability that is generally agreed to be a linchpin technical requirement if mobile robots are to achieve significant acceptance by the defense user community - and one whose technical underpinnings themselves are far from established.

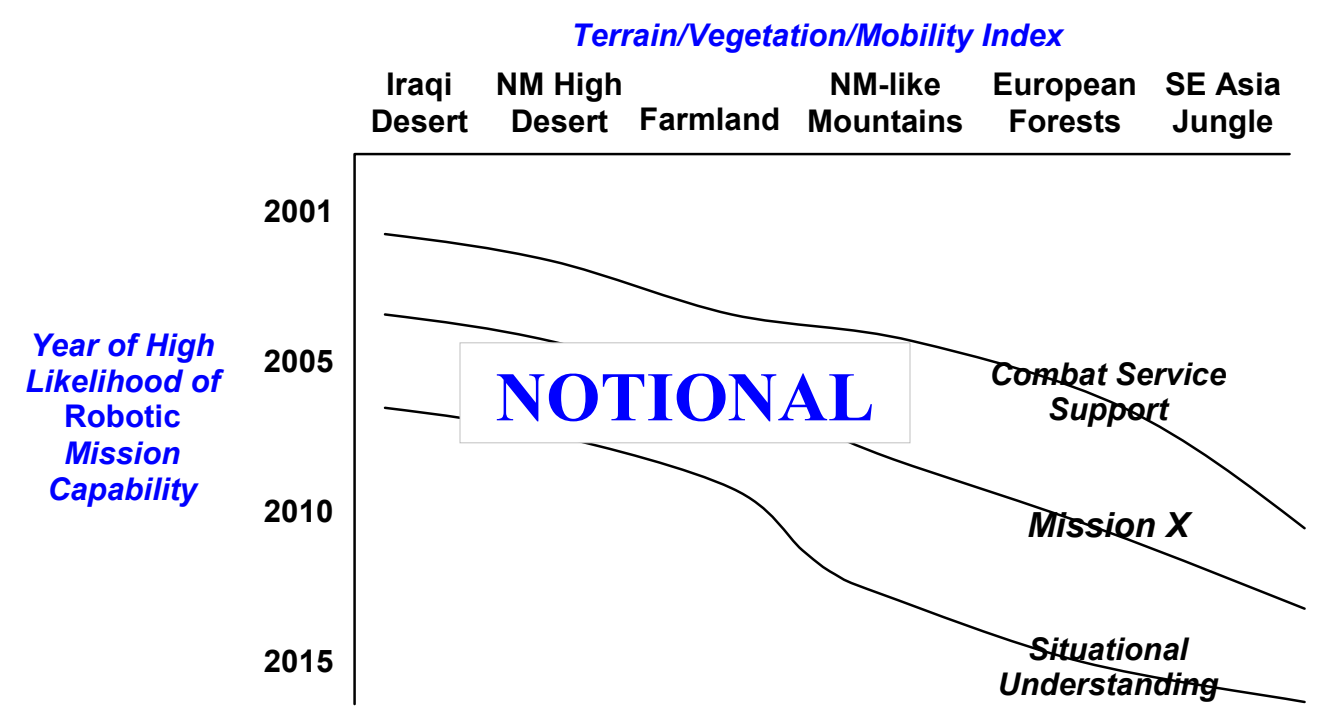

Figure 1: Notional Approach to Top Level Systematics of Ground Mobile Robot Systems 
Because of the author's familiarity with the foothills of the Sandia Mountains near Albuquerque, New Mexico, and his easy access to them, a locale there was chosen for the case study. The terrain in the Sandias will support experimentation and analysis of the technologies needed for a number of the missions envisioned for mobile robots, but reconnaissance and surveillance seemed a particularly good fit to the area, and so it was chosen as the mission to be studied.

\section{The Mobile Robot as a System}

The term "mobile robot" conjures up an image of a machine with components such as propulsion, energy storage, and controls. However, the world in which a ground mobile robot must operate is very complex and forces the mobile robot itself to be a complex machine, including mission and navigation sensors, onboard computing with a complex software suite, $\mathrm{C}^{3}$ hardware and software, and perhaps other components such as devices for remote manipulation. Furthermore, there is a human to machine interface; i.e., the means by which the robot receives commands from a human supervisor. There is an additional facet to this suite of components: the computer models of the mobile robot, its components, its capabilities, plus the models of the environment in which the robot must carry out its mission. It is becoming common to refer to these as the virtual robot and its virtual world; and they are considered to be a component of the overall mobile robotic system. We seek to develop - or at least to begin to understand - the design drivers for an integrated approach to the technology development of this multifaceted suite of components.

\section{Overview of this Paper}

Understanding the technology issues is dependent on being able to understand and visualize the setting of the Embudito Mission; the "where" for the overall mission may profoundly affect "how" the robot will carry it out. The paper thus makes use of a number of photographs of the area as well as its topographic map. It is probably best viewed on the reader's computer and so, in addition to paper copies, is provided on compact disc.

A number of sections follow, beginning with a high level description of the mission. Three following sections focus on differing levels of granularity:

- Requirements at the scale of the mission itself.

- Robot Communication

- Robot Navigation/Position Estimation

- Classification of Vegetation Zones

- Mission Route Planning

- Robot Mobility.

- Requirements driven by the zone near the robot, 20 feet and less, as it performs its mission, focusing on the various kinds of vegetation and "small" obstacles which may be encountered by the robot, and the associated needs for sensing.

- Requirements driven by a larger zone around the robot, 1000 feet and less, as it performs its mission.

- The Virtual Robot and its Virtual World. 
While not exhaustive - robot power and energy are not included for example - these are generally acknowledged to cover the requirements and technologies that must be successfully developed and integrated if autonomous navigation and driving is to be achieved.

\section{The Embudito Reconnaissance and Surveillance Mission}

The Embudito "Mission" is hypothetical: traverse to a location approximately a mile and a quarter behind the near hill in the middle of Figure 2, and from a ridgeback there, perform surveillance on a house and barn at the bottom of a canyon. (For readers familiar with the area, the Embudito Mission starts at the trailhead into the Embudito Canyon. The house and barn are at the mouth of another canyon in the Sandia Mountains - Bear Canyon.) The mission is hypothetical in another important way. The mission is in the foothills of the Sandia Mountains, and is on the edge of the Albuquerque metropolitan area, and as such is used extensively for hiking and mountain biking. This paper ignores all the supporting amenities for those recreational pursuits; i.e., trails. In other words, Embudito is used to simulate a remote surveillance and reconnaissance mission. Future case studies should include trails - manmade or otherwise - as part of their systematic consideration.

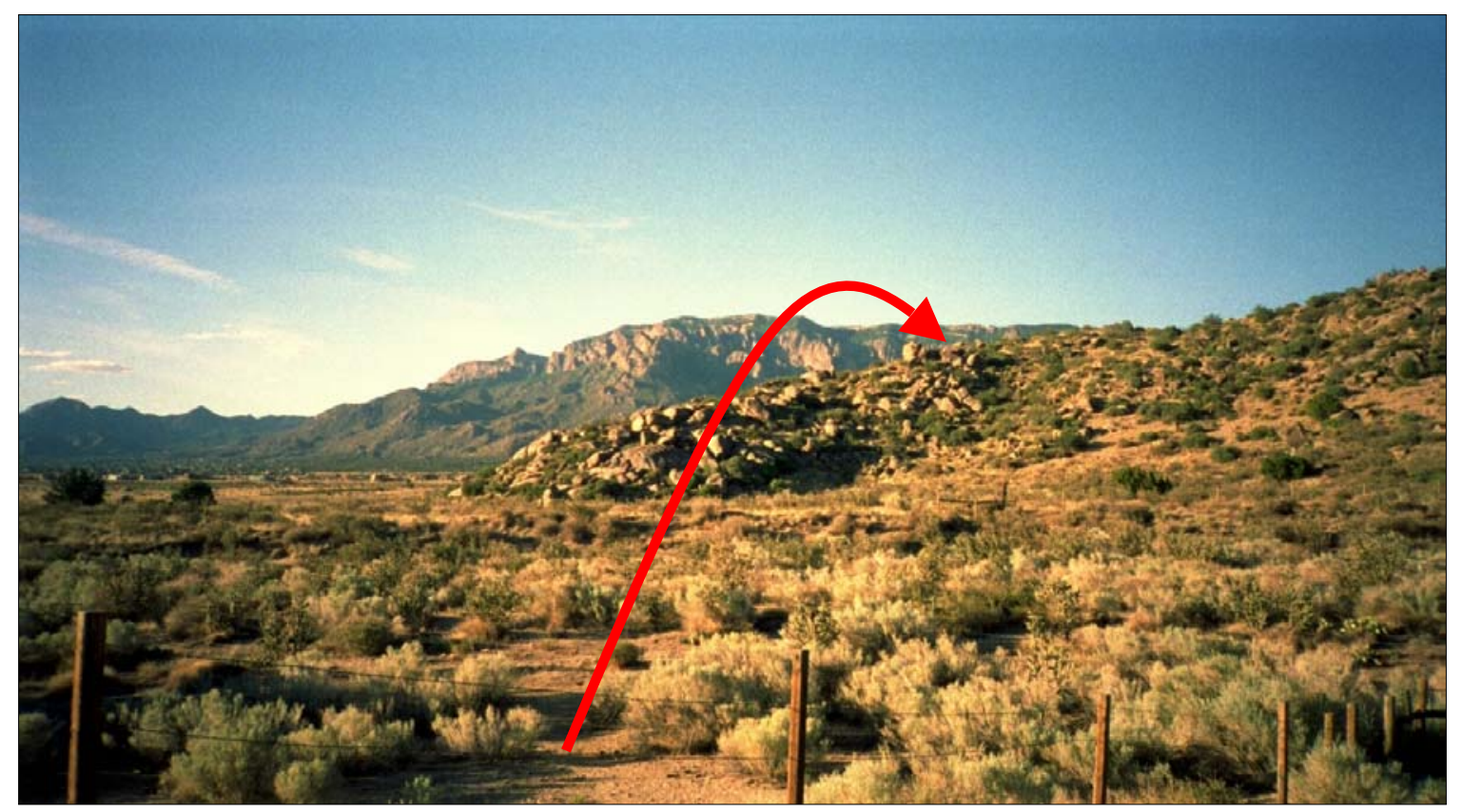

Figure 2: Area of the Embudito Mission in the Foothills of the Sandia Mountains near Albuquerque 
The topographic map of the mission area is another useful, motivating view of the area in which the Embudito Mission is to be conducted. Figure 3 shows the location of the target, the location from which the robot is to observe, and the location at which the robot starts the mission. For reference, the hill in the middle of the previous picture is circled on the left side of the map.

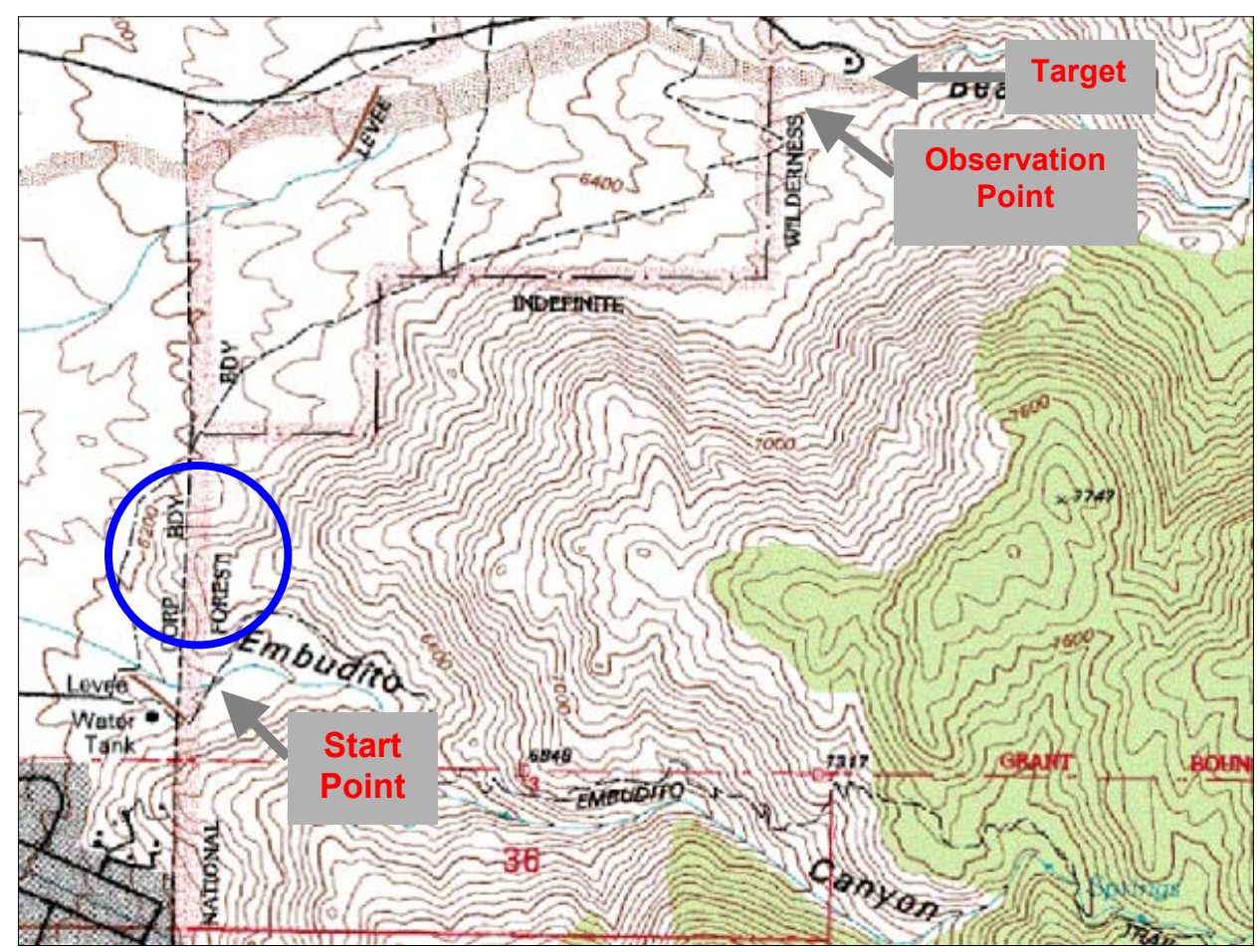

Figure 3: Topographic Map of the Area of the Embudito Mission

\section{Vegetation and Obstacles: The Robot's World on a Twenty Foot Scale}

No discussion of the systematics of autonomous mobile robots could exclude the obstacles that the mobile robots must drive around, or over. For the Embudito Mission, vegetation is the principal obstacle in the area of the mission. Rocks are not a significant issue on this mission, but so-called "negative" obstacles may be. The intent of this section is to provide an overview of the obstacles to the ground mobile robot as it makes its way from Start point to Observation point - the types of vegetation, and negative obstacles.

The plant in Figure 4 has a characteristic dimension $(\mathrm{ChD})$ of somewhat more than a foot, not including the spike. For robots with a $\mathrm{ChD}$ of a foot or less, the plant will be driven around rather than over. 


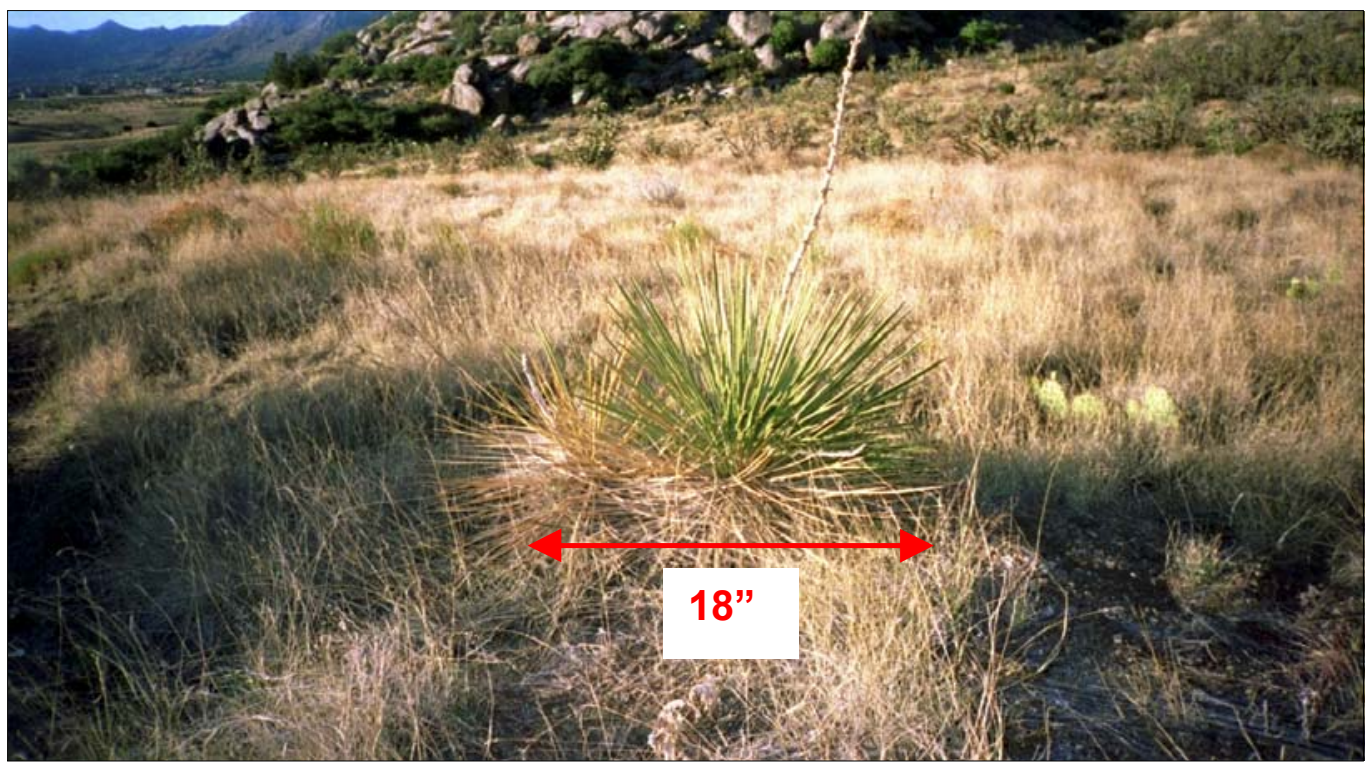

Figure 4: "Sword” Plant

The plants in Figure 5, a cactus and some sort of bush - which could be good to hide in are probably obstacles to be driven around. They are approximately three feet tall.

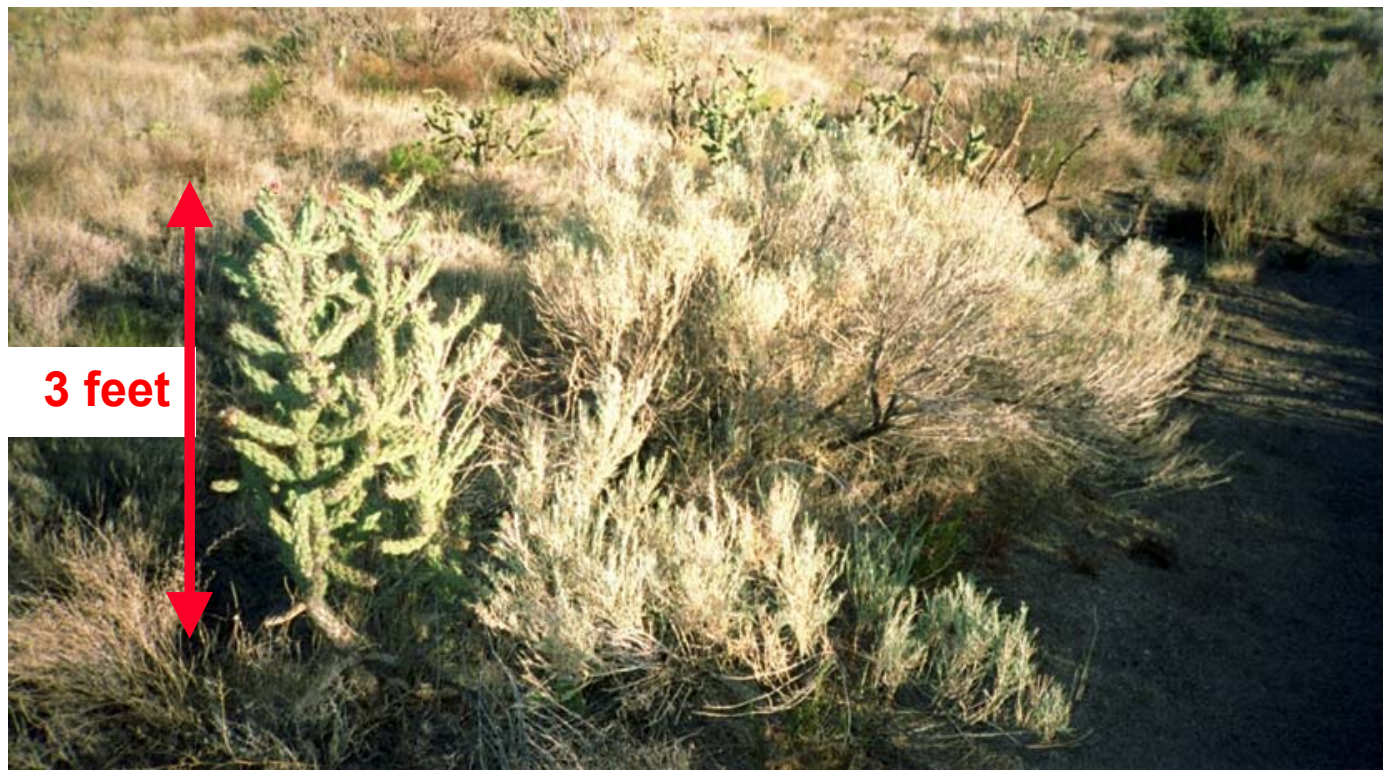

Figure 5: Cactus and Bush

There are larger obstacles, such as the bush and juniper-like tree in Figures 6 and 7, with widths on the order of 15 feet. The same comments about driving around the obstacle and about hiding are apropos. In addition, these large obstacles may be visible on aerial maps, and perhaps should not be called "obstacles" at all. Furthermore, they may provide the possibility, discussed below, of "vegetation-aided" navigation. 


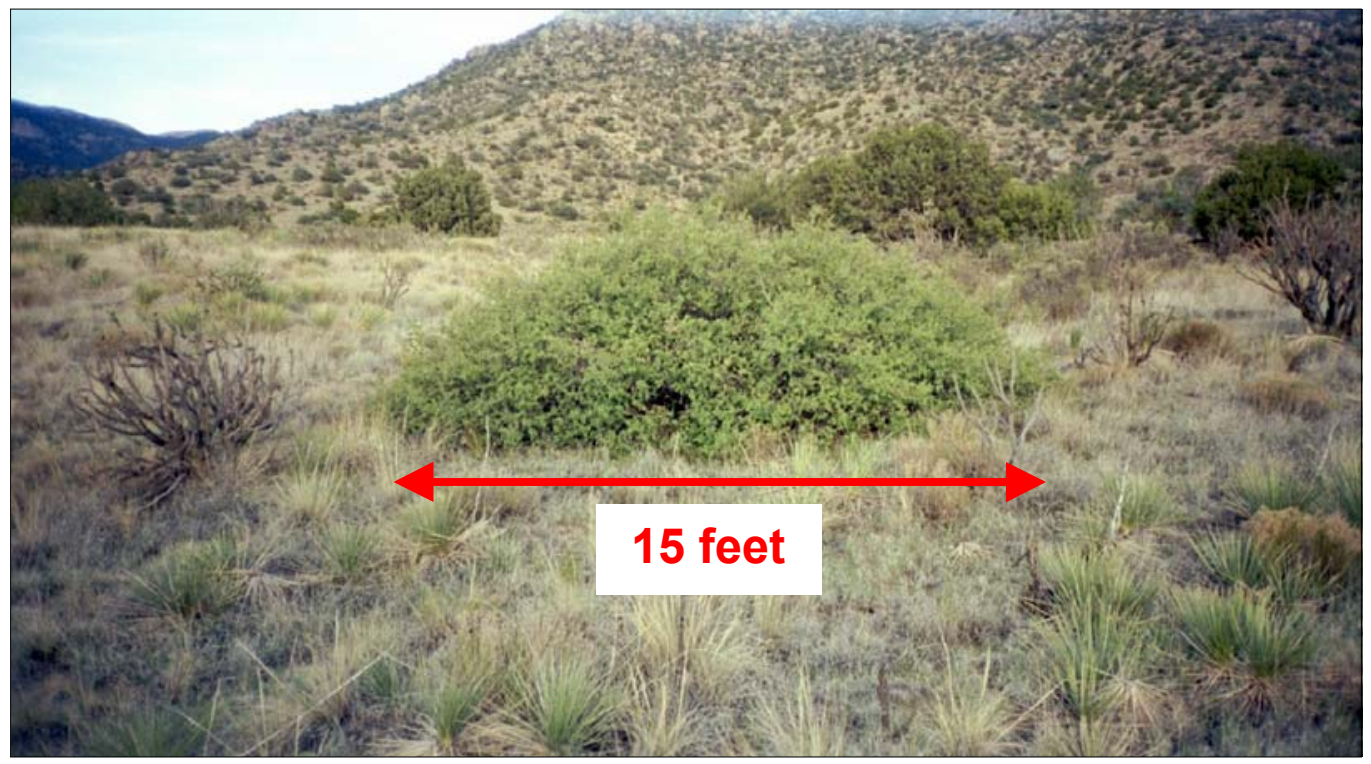

Figure 6: Large Bush

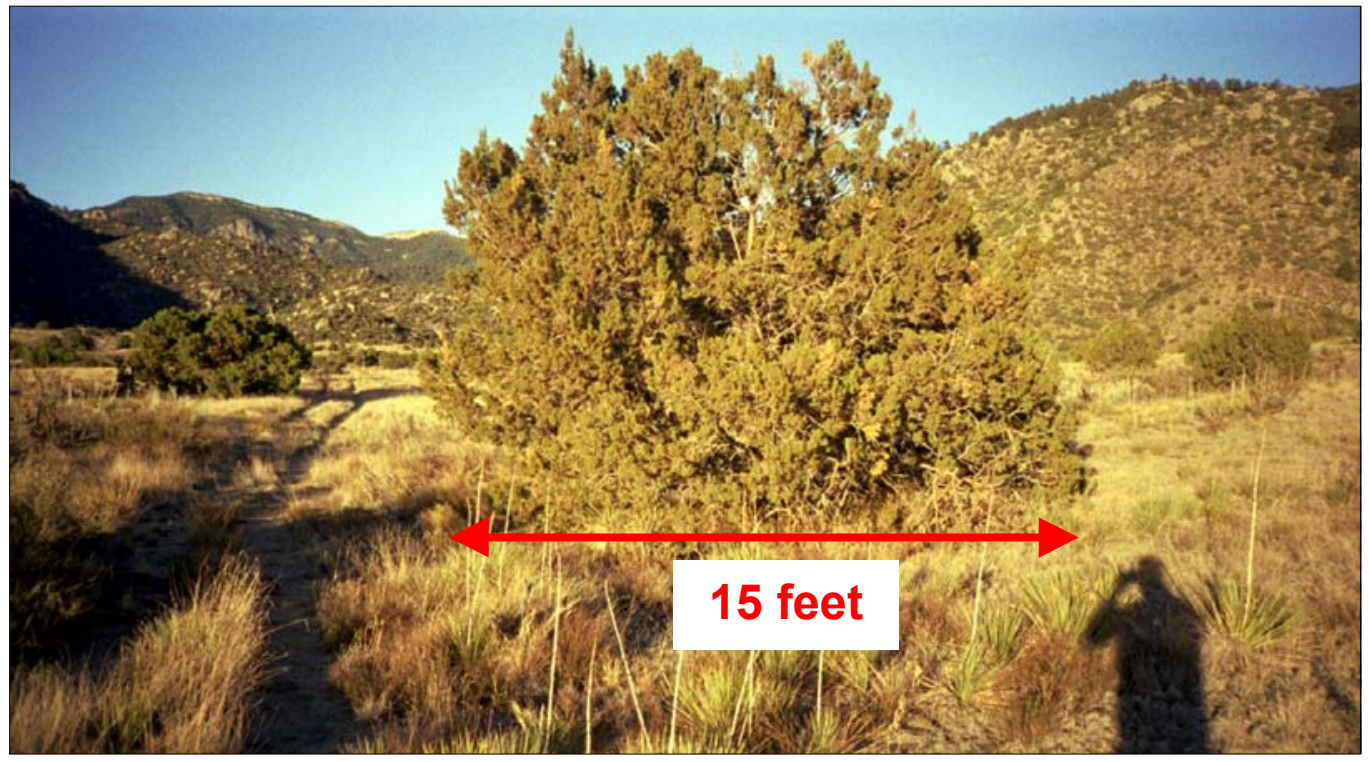

Figure 7: Juniper-like Tree

Figure 8 shows a grass clump, with a ChD of 12 to 18 inches. There is a great deal of this in Embudito, often at a density greater than seen in this photo. It is not an obstacle in the classic sense; i.e., most robots will simply drive over it. But it may have a deleterious effect on a robot's odometry because it is slick and is likely to cause slippage of whatever tractive mechanism is used by the surveillance robot. 


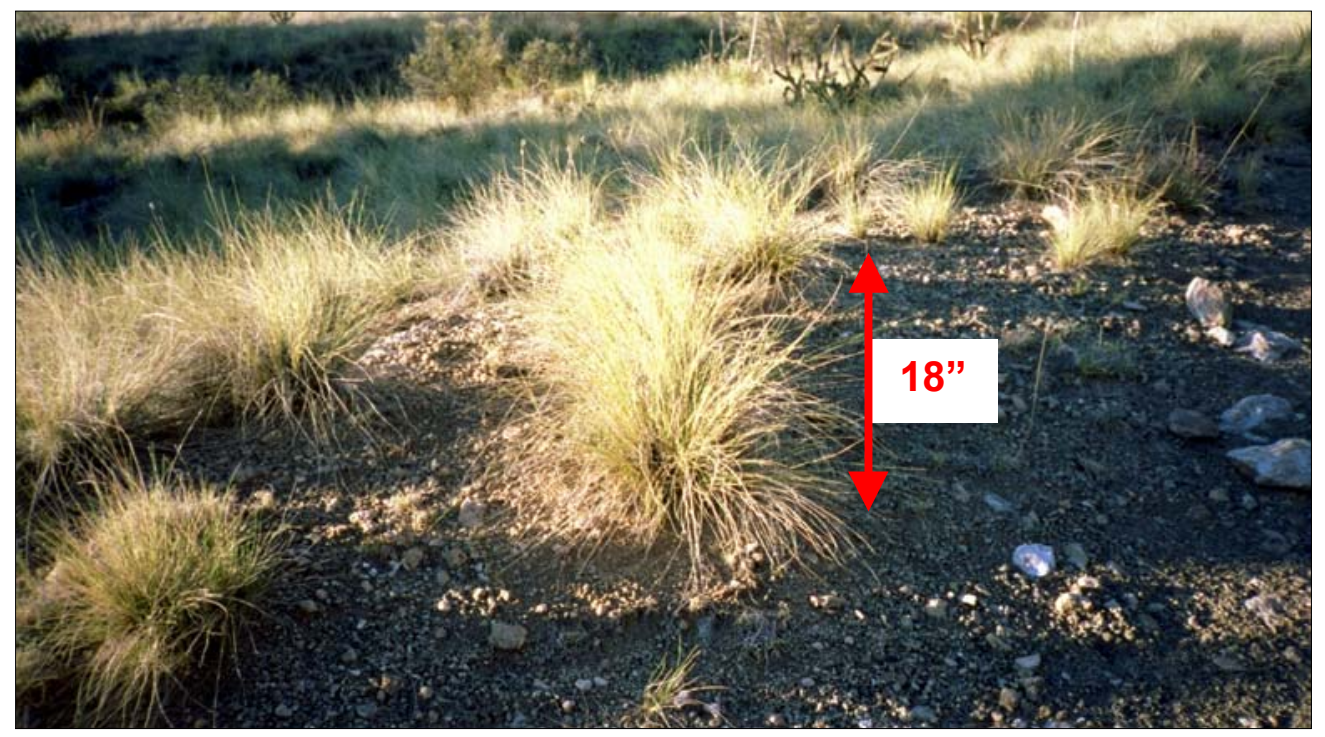

Figure 8: Grass Clump

Tangles of weeds and bushes as illustrated in Figure 9 - three to four feet high and typical of, but not confined to, the bottom of arroyos - have got to be killers when it comes to autonomous navigation and driving: "What lies ahead? How long does this stuff last? What are my absolute coordinates?" Remember that an autonomous robot is moving in terrain that is unmapped - at least at this scale. On the other hand, it might be good for the robot to travel in or near such thickets in case a momentary hiding place is needed. What sensing and control systems will enable such a tactic?

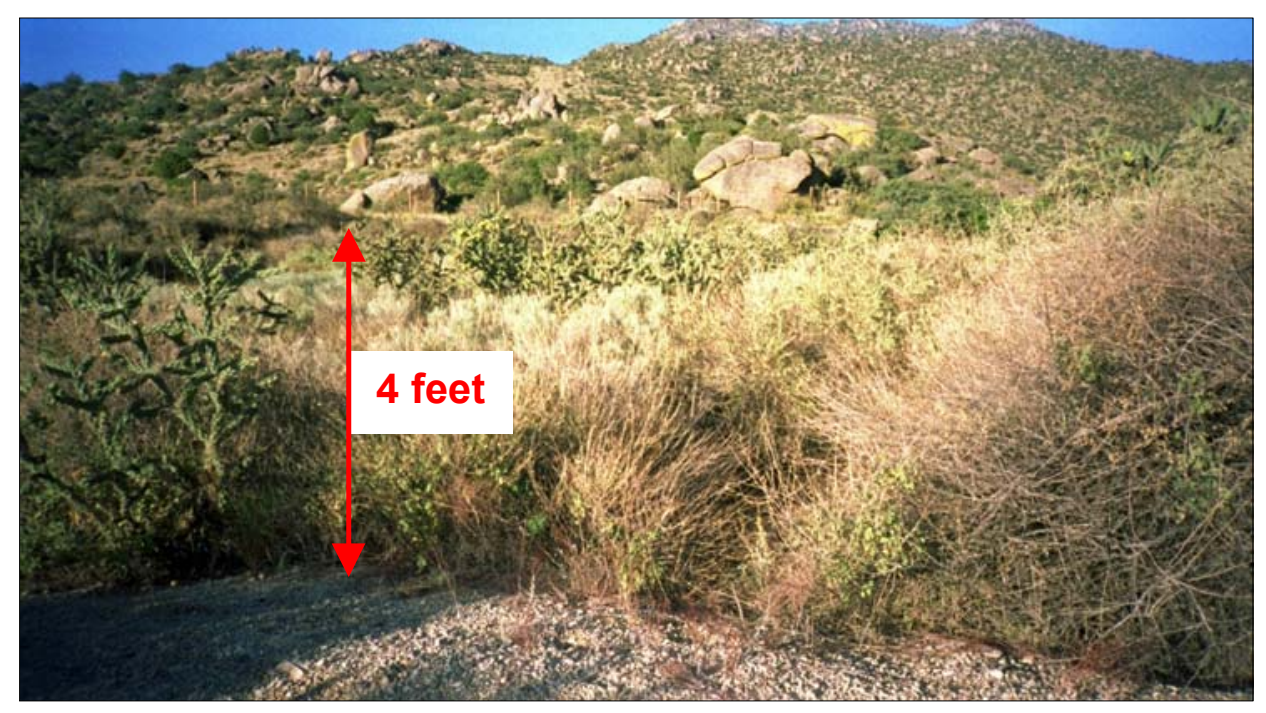

Figure 9: Tangle of Bushes and Weeds

The vegetation in Figures 4 through 9 can be thought of as "positive" obstacles because the weeds and bushes stick up from the ground the robot is travelling on. Holes - termed negative obstacles - present the mobile robot with another mobility problem: falling in 
and being unable to get out, or suffering some kind of damage. Figure 10 shows a small arroyo - ten feet across and three feet deep - with a rather rapid drop on the near edge. It's the kind of situation that can/might overturn the robot if it were driving at too high a speed. From this height, it's believable that the right sort of sensor system would find the edge of the arroyo - as a rapid elevation change. This photo was taken from eye level about five and a half feet above the ground.

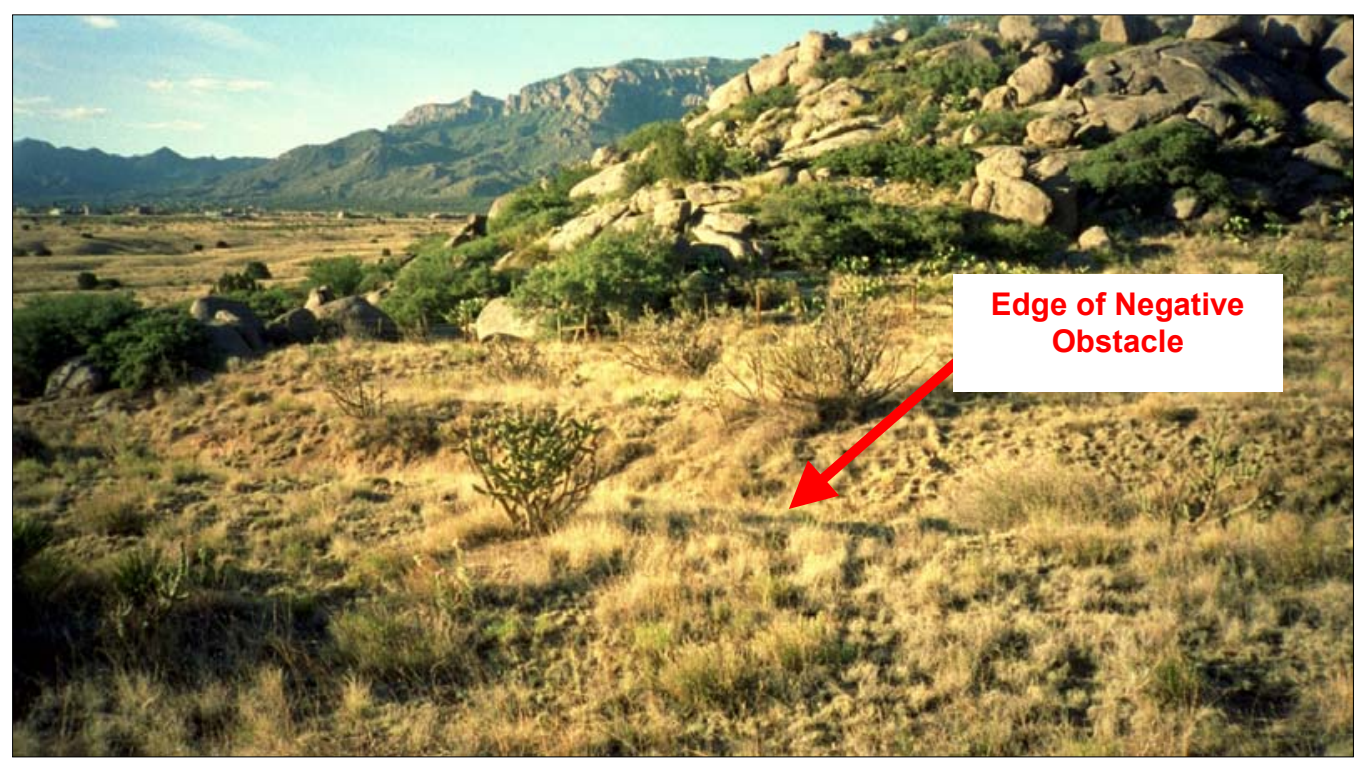

Figure 10: Negative Obstacle from About 5 1/2 Feet Above the Ground

The same arroyo was photographed from 18 inches or two feet above the ground - the height at which a robot's forward-looking sensors will be situated if there is no means of providing greater height to its sensor package. It is easy to understand why automatic detection of negative obstacles is difficult. 


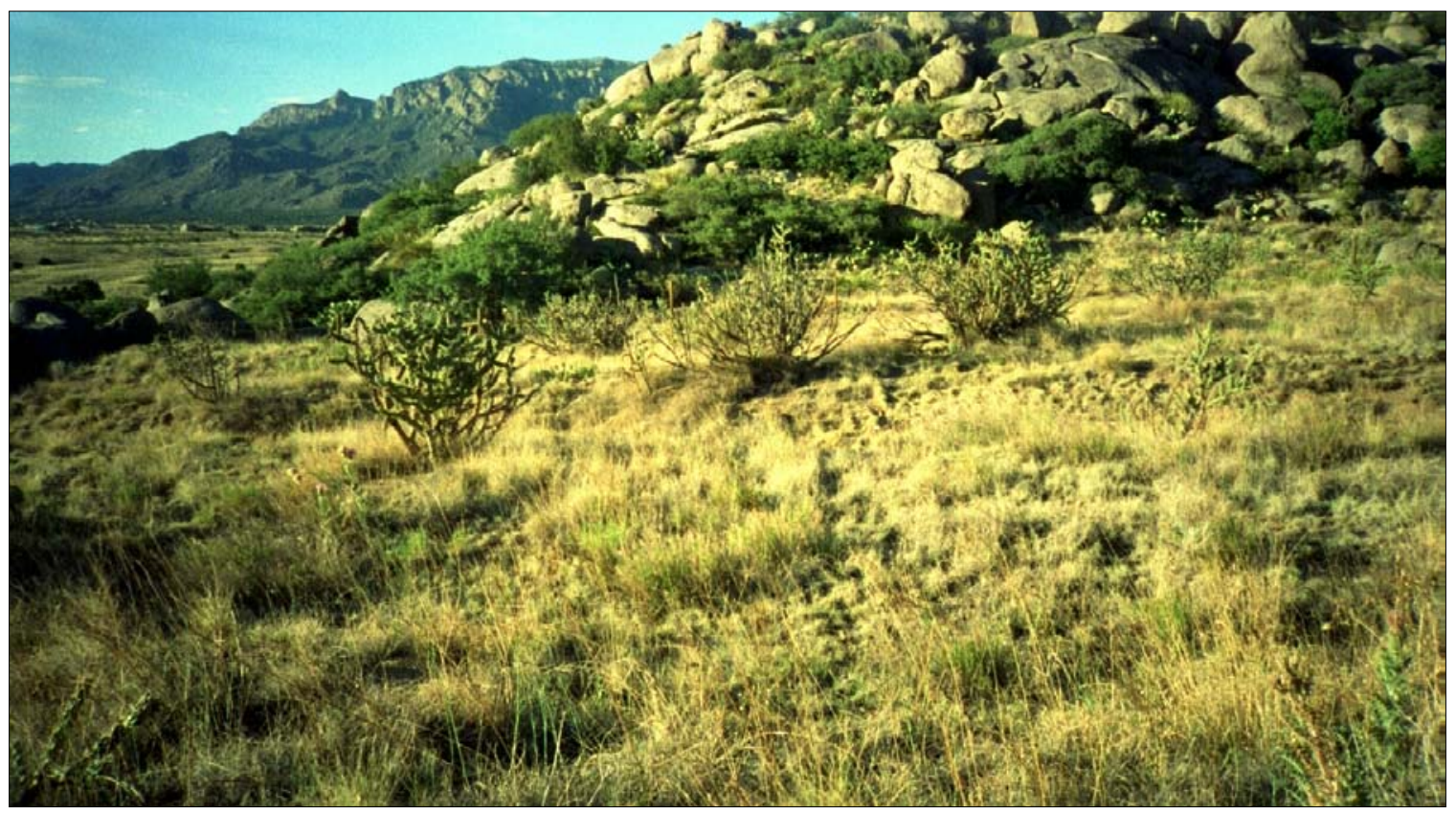

Figure 11: Negative Obstacle from About Two Feet Above the Ground

Figures 10 and 11 present a reasonably complete compendium of the relevant types of obstacles in the area of the Embudito Mission. No systematic methodology exists which deals with the requirements for onboard sensing that will enable mobile robots to autonomously negotiate such obstacles. As a result, the robotics community cannot yet assure defense designers that systems of sensors can be designed which will "assure" mission success - even though there has been much research on sensors for obstacle avoidance, and several successful demonstrations.

\section{Terrain and Vegetation Density:}

\section{The Robot's World on a Thousand Foot Scale}

The section on Vegetation and Obstacles focused on regions near the robot of $\mathrm{ChD}$ up to 20 feet or so. We now look at regions of $\mathrm{ChD}$ on the order of a thousand feet. It will be seen that in the region of the Embudito Mission, which itself has a $\mathrm{ChD}$ of about a mile and a half, there are vastly differing terrains and densities of vegetation. Here, the choice of "one thousand feet" is rather arbitrary: As will be seen later in this section and in the section on route planning, it may be useful for the robot to have some capability to look ahead on its route to avoid unmapped zones of difficult mobility.

The area in the foreground of Figure 12 - a ridgeback between two arroyos - looks like a great place for an autonomous mobile robot to drive because there are few obstacles just the grassy clumps - and lines of sight to GPS and comm links are probably quite good. Unfortunately, it may not be a desirable place for a reconnaissance robot to be traveling; the same things that make it a good place for the robot to be driving might make it a bad place because the robot could be a sitting duck for hostile observers. 


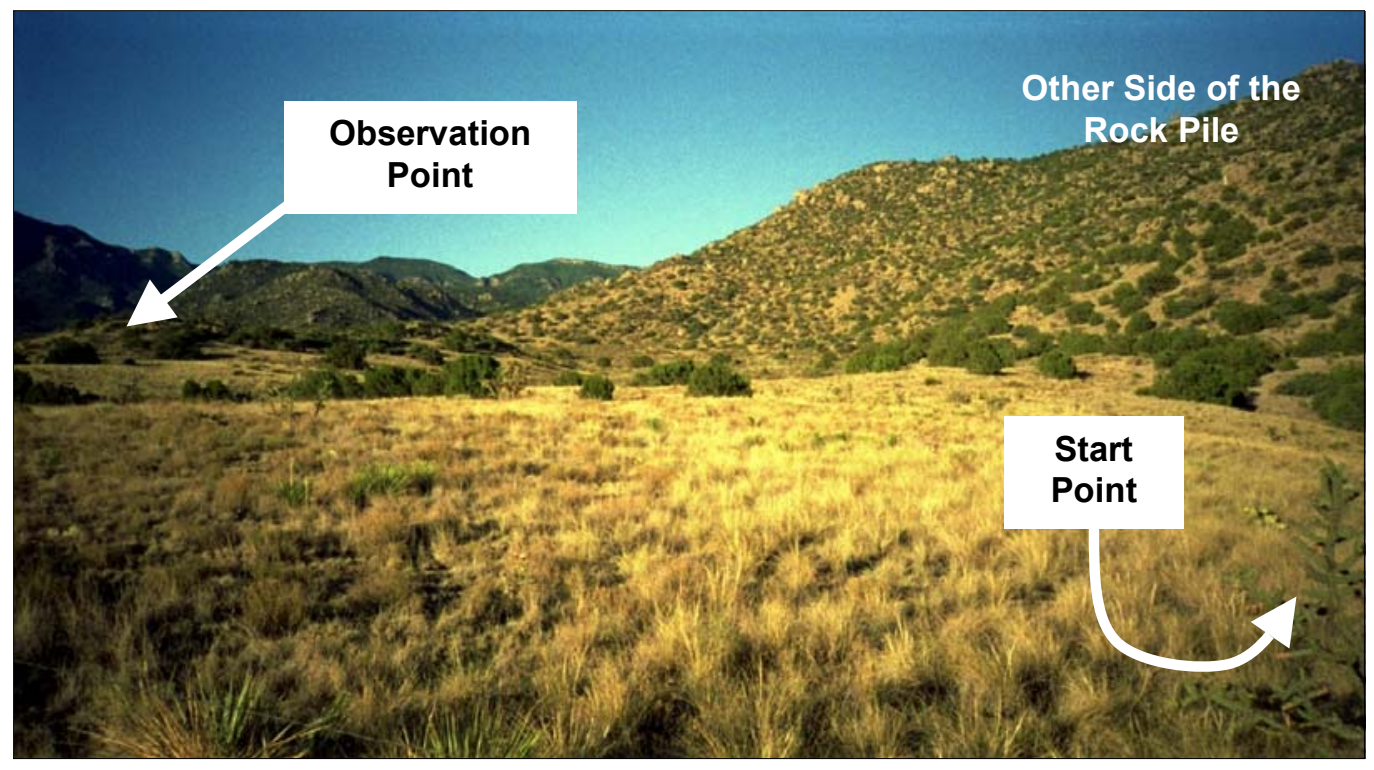

Figure 12: Ridgeback

A really good reason will be required for robots to go into piles of rock - pebbles to 15 foot boulders - as in the center of Figure 13. (But a really good reason could be that the rockpile would help to hide the robot as it was driving from Start Point to Observation Point.)

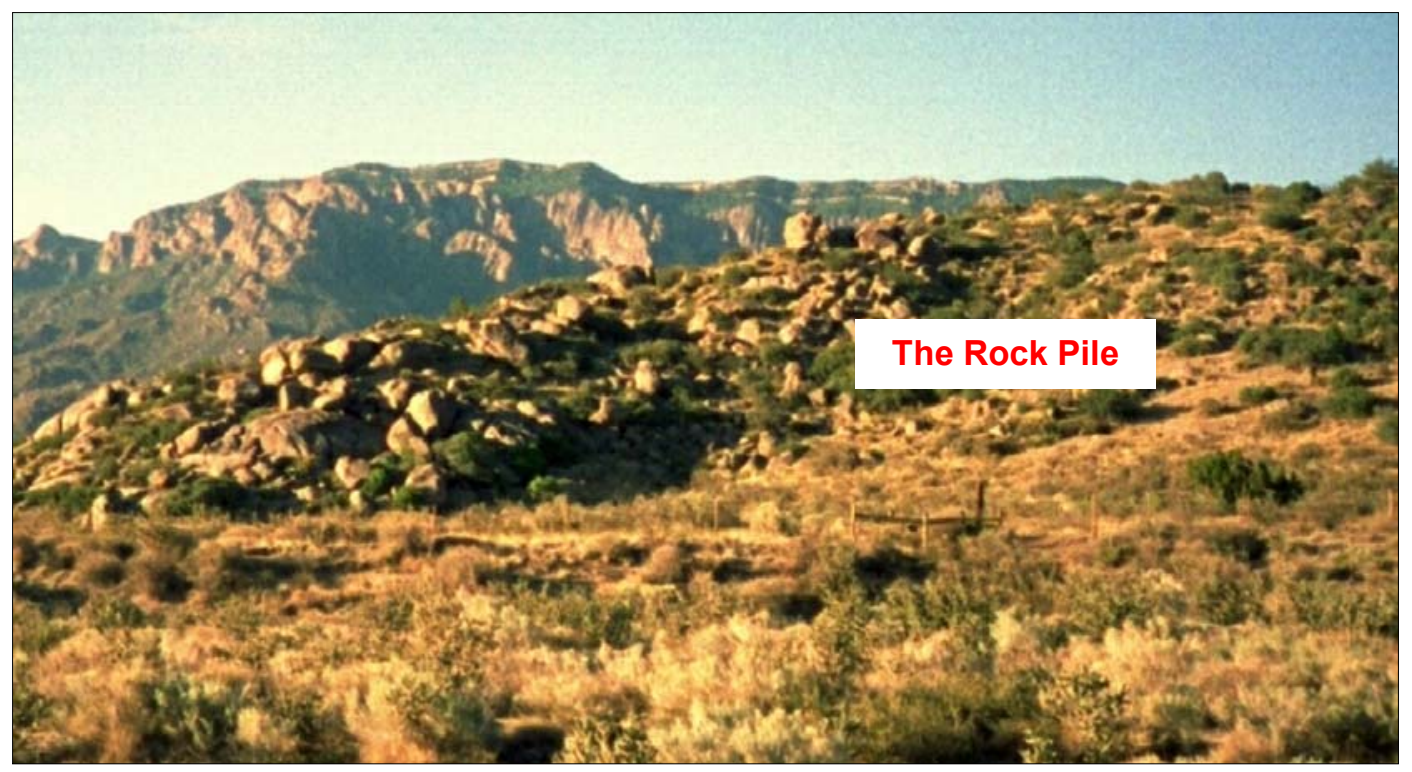

Figure 13: Rock Pile Between Start and Observation Points

The site pictured in Figure 14 is interesting. The foreground contains fairly rough vegetation, but could be a reasonable place to traverse - or to hide - for the correctly sized 
vehicle. It's noticeable that there is a fair amount of large vegetation at the base of the hill. Since this seems to be fairly common in Embudito, it is interesting to speculate whether ecologists could predict such vegetation.

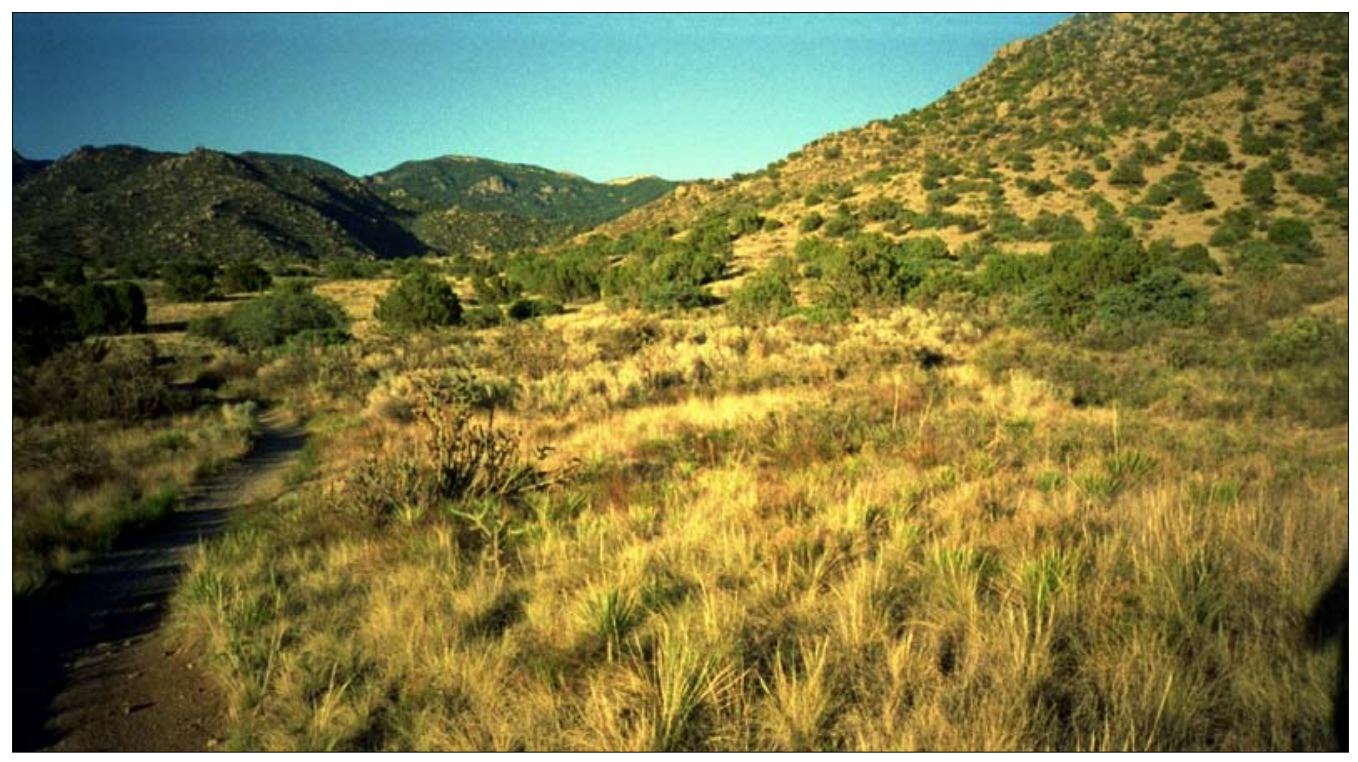

Figure 14: Area Near the Base of a Foothill

From the standpoint of autonomous driving, the bottom of the arroyo in Figure 15 is a mess, consisting of a thicket of various bushes and weeds - an earlier picture showed such a thicket. Just as with the Rock Pile, it's difficult to believe that it's desirable for an autonomous robot to drive for long distances there. The other side of the coin is that the thicket is a very good place for robots to hide.

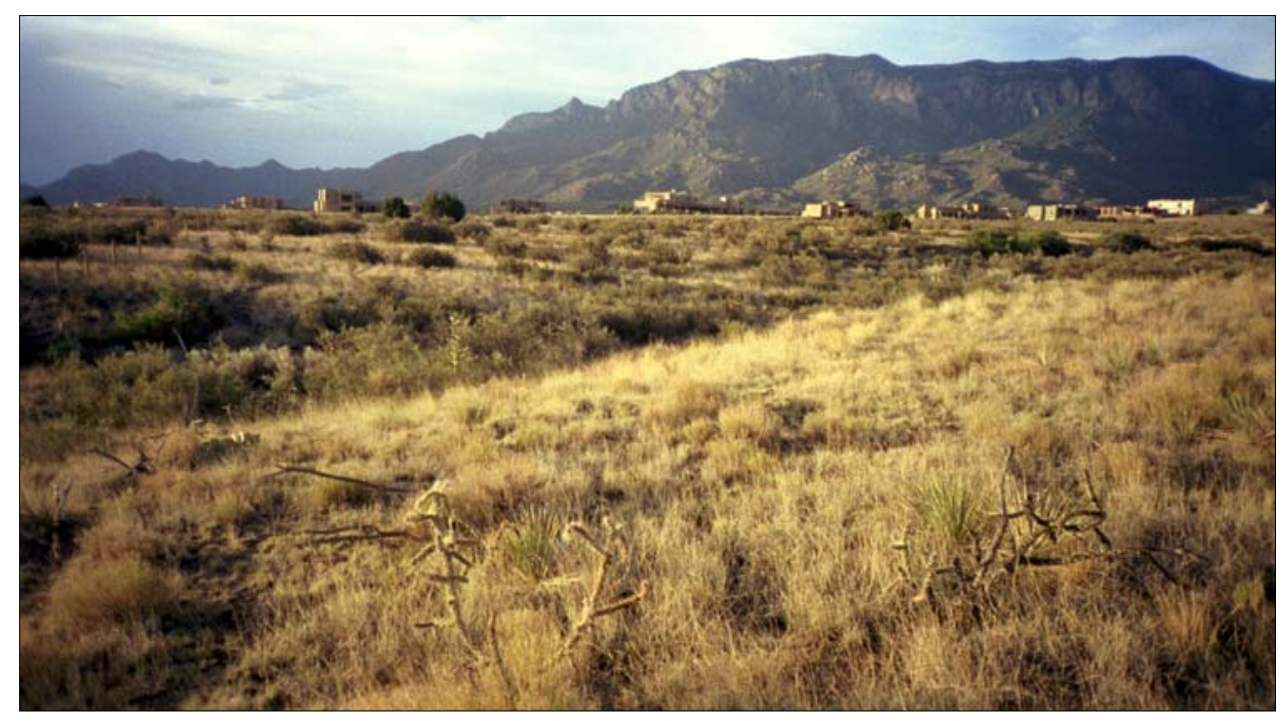

Figure 15: Two Sides and Bottom of an Arroyo 
The near side of the arroyo looks like an ideal place for driving because it has very few obstacles of a size that would be troublesome. The far side could also be ideal because it has obstacles which are not very numerous from the standpoint of autonomous driving, but which could provide some hiding places for a surveillance robot as it is moving to its Observation Point.

The photos in Figures 16 and 17 illustrate how drastically the density of vegetation can

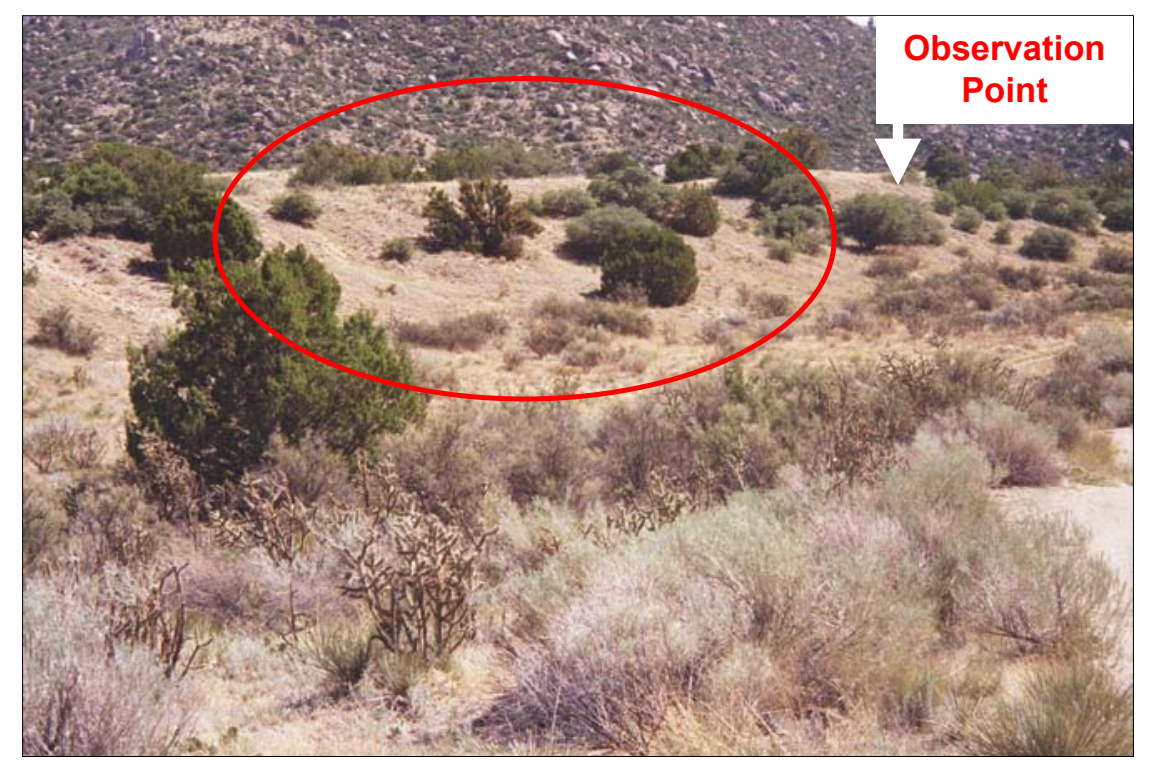

Figure 16: Looking Northeast Toward Observation Point

vary just by being on different sides of an arroyo. The top photo looks northeast toward the ridgeback on which the Observation Point is located. Note that the vegetation mainly trees and bushes - is fairly sparse. The foreground in the photo contains fairly dense vegetation. Figure 16 looks the opposite direction; i.e., from the ridgeback southwest toward where the top photo was taken. The vegetation on that side of the arroyo - cactuses and small bushes in the middle of the picture - is relatively dense. This variance of vegetation on opposite sides of arroyos in Embudito seems to be fairly consistent. 


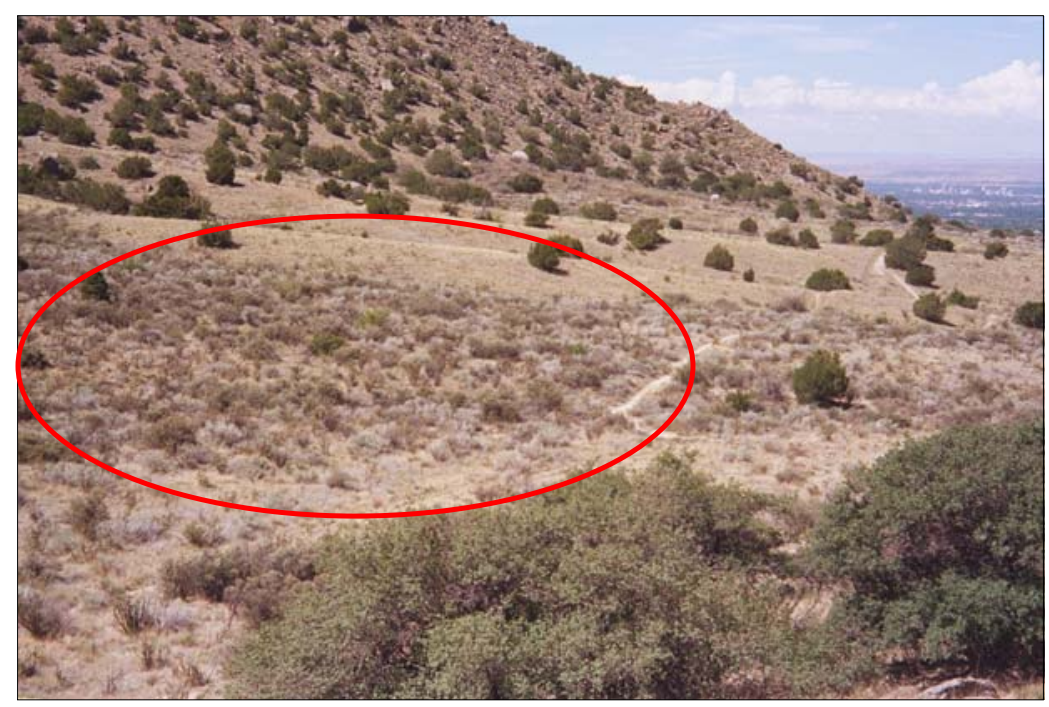

Figure 17: Looking Southwest From Near the Observation Point

The photos in this section have presented a reasonably complete compendium of the important types of traversal regions in the area of the Embudito Mission. It is useful at this point to talk about the quality of maps that will be available. Obviously, there are missions of such high value - a value that will admit to very high precision pre-mapping of the mission area - that even some of the obstacles in the Vegetation and Obstacles section will appear. But for most missions, for the foreseeable future, maps showing most of those obstacles will be prohibitively expensive. The fundamental question then is how autonomous robots could obtain the information that will permit them to successfully and effectively traverse such regions. If we provide robots with good obstacle sensors; i.e., the ability to see unmapped objects which are immediately in front of them, then we will have done little more than the equivalent of providing a visually impaired person with a cane. If the robot is also equipped with the right navigation sensors - which do not yet exist - then it could eventually succeed in getting to the Observe point - providing that it didn't wander into a traversal region for which it did not have either the intrinsic mobility needed to escape or the memory required to backtrack. (By what means would an autonomous robot decide that it needed to backtrack? Hmmm.) This issue seems to argue for a lookahead sensor that has some minimum coarse resolution. Some programs have addressed this problem by fitting the robot with an extendable mast for a look-fromabove sensor, but much work remains.

By integrating the information in this section with that of the Vegetation and Obstacles section, it is easy to see why it will be difficult for mobile robots to autonomously negotiate the terrain and vegetation of the Embudito Mission - or any other except the simplest. And yet they must, if mobile robotics are to achieve significant acceptance. No methodology has been defined which will permit the robotics R\&D community to systematically address the requirements for sensing and automated planning at such an intermediate granularity - and yet such sensing and planning may be necessary to avoid zones of difficult mobility. 


\section{Requirements at the Scale of the Mission Itself}

\section{Robot Communication}

The mission of the Embudito robot is to perform surveillance on several remote structures. Perhaps the surveillance job is to snap one photo and return to the Start Point with the photo stored in the robot's memory. But if the mission is to perform continuous real time surveillance then the robot must have a means of communicating information "continuously" to some command center. It should be obvious from pictures above that there is not line of sight communication between Observation Point and Start Point. If a satellite or air vehicle is available, then it may be the means of relaying the data. But if not, another means of information relay will be needed; for example, the robot itself could carry relay devices - marbles - and drop them off at the "correct" locations.

In addition to the need to send mission-related data back to a base, any robot - even an "autonomous" robot - will likely need a capability to ask for help. For example, it might enter an unmapped zone in which it is too difficult to make progress toward the Observation Point; a thicket of weeds or bushes might be such an example. There are a couple of possibilities. The robot may have enough of a map and mission planning brains onboard to re-plan its strategy. Or it may need to communicate with its human commander; in this case, a set of communication marbles might be required to enable the communication. Consider Figure 18. It seems obvious that a mission planner - human or computer - would define the locations at which the robot should drop off communications marbles - a subset of the ridgebacks on the robot's nominal route seems like an obvious choice. However, no strategy that will satisfy either or both of mission data or help-line communication has been studied, defined, developed and tested. And there is no methodology for thinking about the tradeoffs between communication for help and onboard replanning brains.

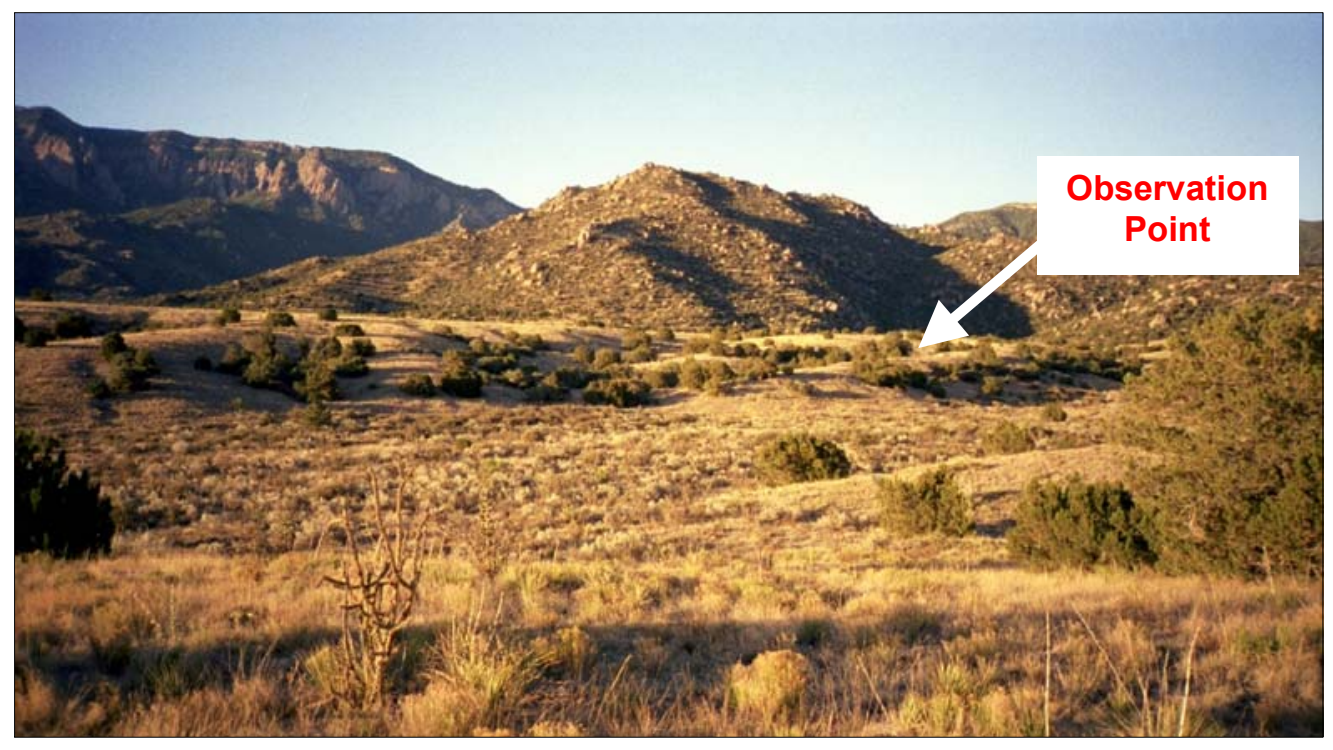

Figure 18: Line of Sight Between Observation Point and One Point on One Path 
Strategies for communication must be developed which will permit comparison of various ground relays, such as the marble, with space and airborne relays. And there is no methodology for thinking about the tradeoffs between communication for help and onboard replanning brains. Today there is no systematic means to consider these issues.

\section{Robot Navigation}

As a small example of the importance of navigation, if an autonomous robot is to drop off a communications relay at a particular spot, the robot must obviously know where it is relative to that spot. A robot's navigation system provides the robot information on where it is in the world; i.e., its internal estimation of position. To begin our systematic thinking, it is interesting to do a conceptual comparison of the navigation needs of ground mobile robots with those of cruise missiles. Cruise missiles must get to a target within some circular error probable. And they sometimes fly complex routes; video of cruise missiles flying along city streets, while avoiding buildings, are memorable. These capabilities depend on a very capable navigation system that knows "precisely" where the missile is at all times. How will ground mobile robots get this same information? Cruise (and ballistic) missiles use inertial navigation systems, and there are groups considering their adaptation to ground mobile robots. But it is not yet known if they will work adequately or whether they can be made as cheaply as may be required for ground mobile robots. (In addition, the mobile robot's navigation problem seems more complex than that of the cruise missile; the robot must dodge unknown obstacles while the cruise missile flies a pre-determined mapped route.) GPS is another possibility, but is subject to dropouts because terrain and/or vegetation blocks the GPS signal - look at the picture above to understand how that can occur. GPS is also subject to jamming. The mobile robotics literature is rich with varied schemes for navigation including odometers, compasses, and altimeters.

There is also literature on landmark recognition whereby a robot, as it moved along would recognize features, which are at known locations. In Figure19, there is a 1-meter resolution (claimed) aerial photo available on the web. (Embudito's biking and hiking trails are obvious.) In addition, there are a bunch of black blobs on the picture; two are within the red circle near the center. A photo of them is on the right below, and they are located at the $\mathrm{X}$ in the topographic map at the left below. Whether such information would be valuable to a mobile robot navigation system is unknown, but one must ask if such vegetation could act as passive "beacons" for a robot's navigation system. 

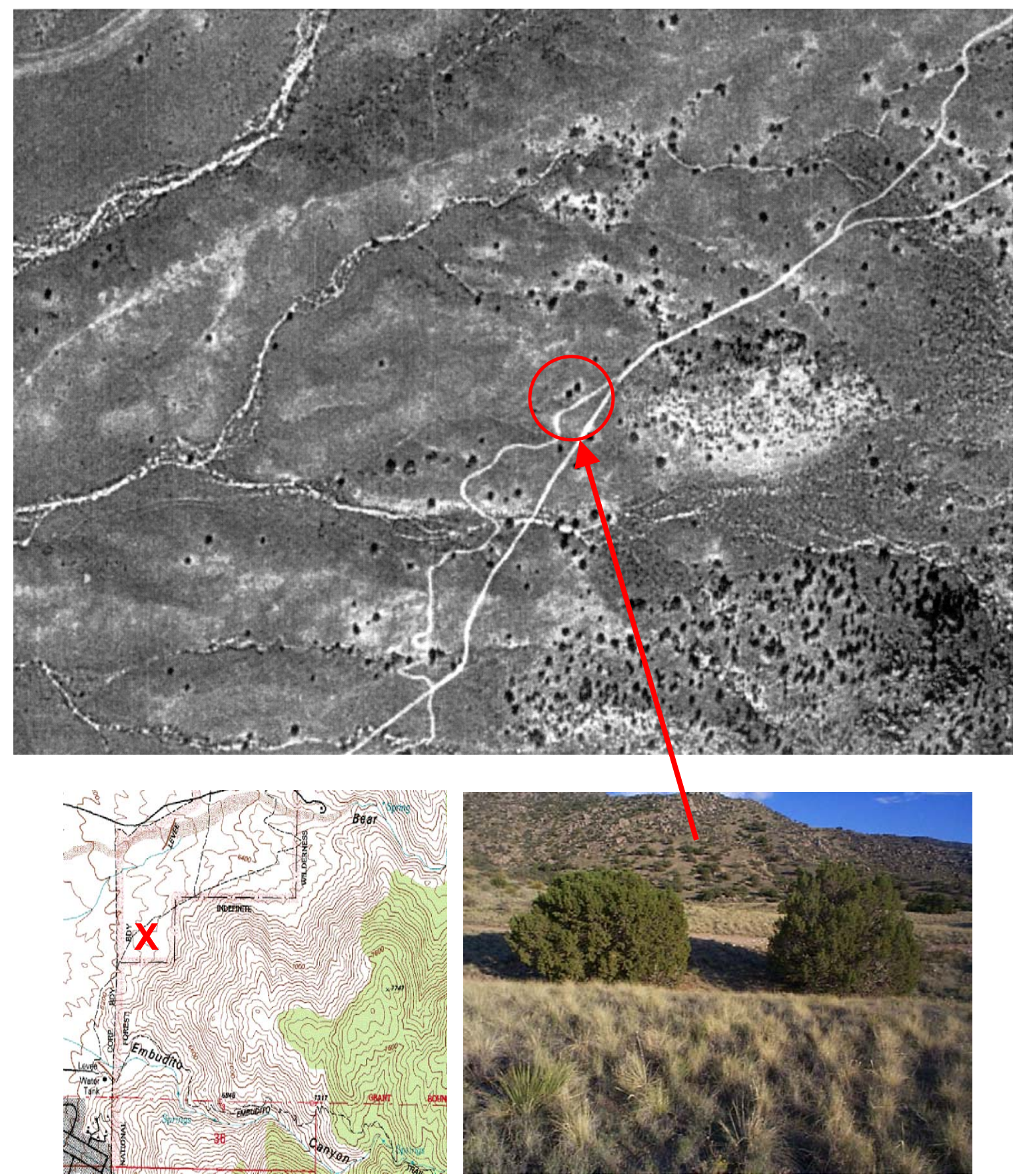

Figure 19: Vegetation Observable in Aerial Photos at Embudito

There is no systematic methodology that will permit analysis of the various possibilities for autonomous navigation of mobile robots. It is especially important that no methodology exists which takes into account the positive and negative effects of obstacles. Furthermore, in contrast to cruise and ballistic missiles, there is no systematic methodology for describing the requirements for navigation accuracy. 


\section{Classification of Vegetation Zones}

The Terrain and Vegetation Density section pointed out the wide variability in zones of vegetation in the area of the Embudito Mission, and, in addition, discussed the impact of the different zones on the robot's ability to reach the Observation Point. Study of the aerial photo in the section on Navigation raises the interesting possibility that zones of vegetation can be automatically classified in a way which will assist the robot's route planner to select good routes. Note the area on the right side of Figure 20 - the darker and "fuzzier" part. This is not an artifact of sun angle or orientation of the camera to the ground; it is an area of high vegetation density. Can zones of vegetation be automatically classified using aerial photographs? The answer is almost assuredly yes - compare Figure 21 with Figure 20. There must be a rich literature on automated classification. But has the work developed classification schemes which will be useful to route planners? This is not known.

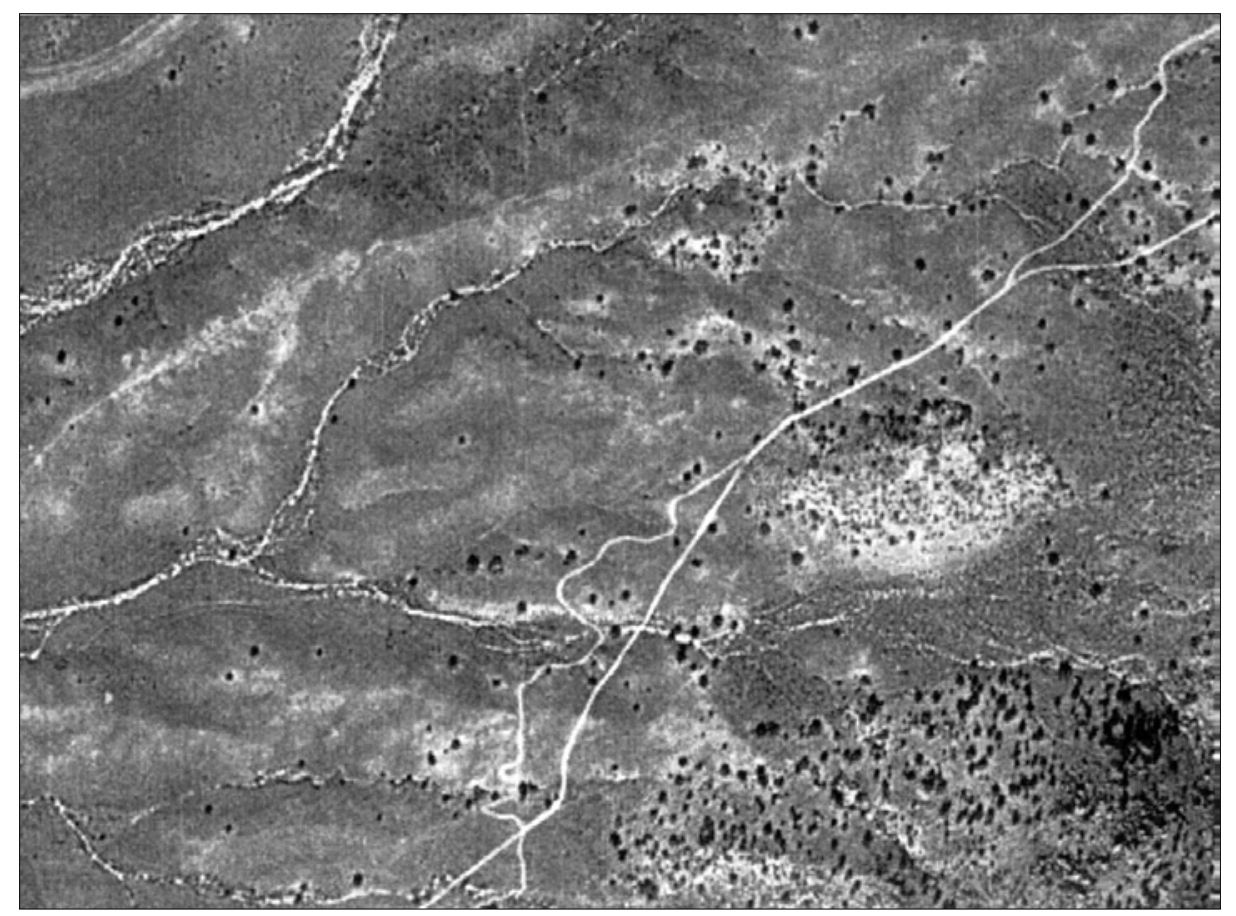

Figure 20: 1 Meter (Claimed) Resolution Aerial Photo in Embudito Area 


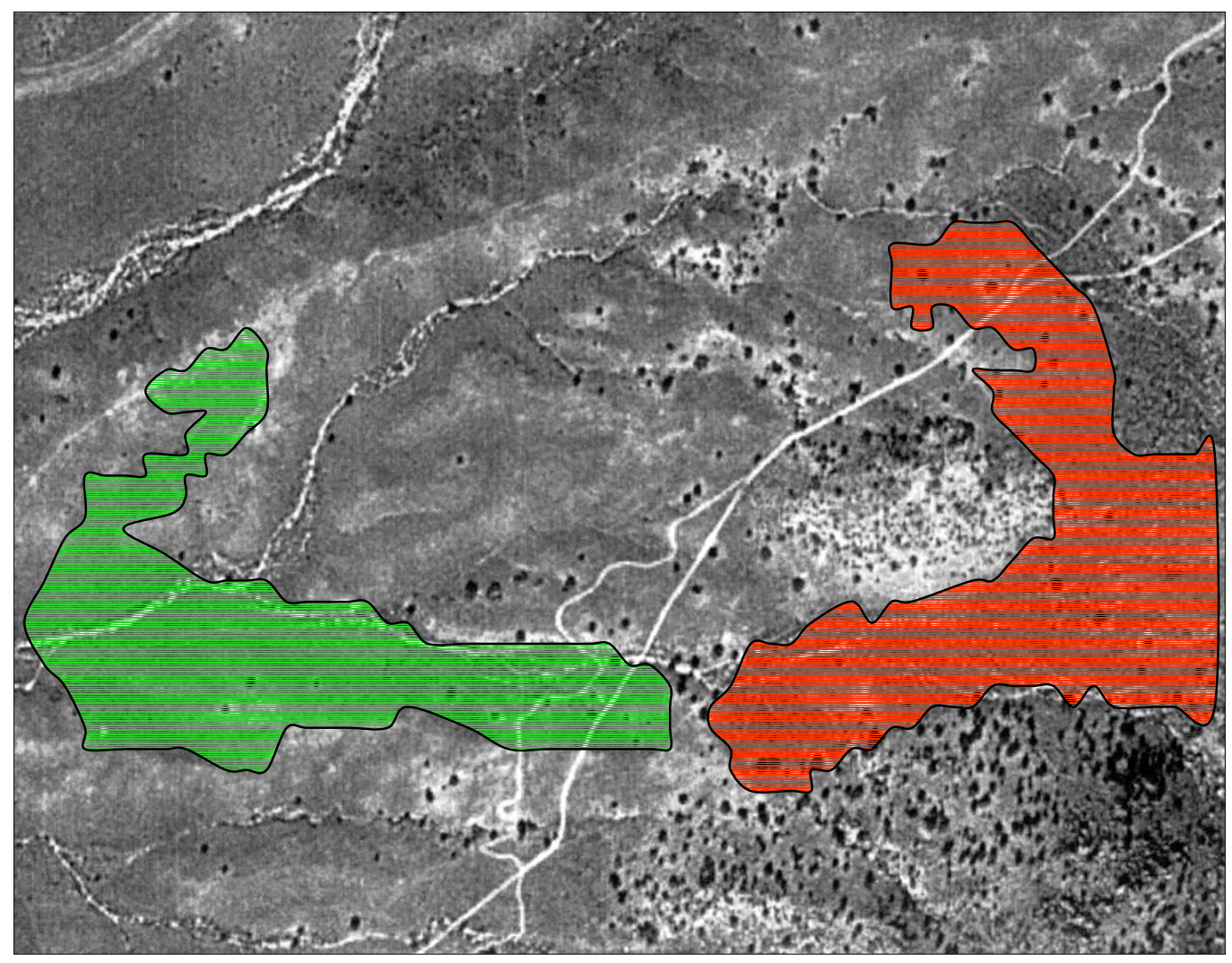

Figure 21: Vegetation Zones Visually "Classified”

\section{Mission Route Planning}

Given a nominal route from Start Point to Observation Point, an autonomous mobile robot is expected to be able to execute that route - or something approximating it - on its own. But how does the robot - or its human commander - decide on the route? At a deeper level, we should understand why this is even an issue; unfortunately this will cause us to delve a bit into the arcana of teleoperation versus autonomy. (Even the lingo here is not very well agreed upon; tolerance is requested.) A teleoperated robot is one whose every motion is controlled by a remote human operator who decides on movements by using a robot-mounted camera to observe the terrain and vegetation near the robot. Let us paint the picture at the two ends of the teleoperation/autonomy spectrum:

Teleoperation: For the Embudito Mission, the soldier-operator of the robot would likely have supplemental information such as a digitally displayed topo map, perhaps even capable of displaying the robot's estimated position on the map in real time. $\mathrm{He} / \mathrm{she}$ would begin the mission by making a decision about a seemingly good route, and then drive the robot, avoiding obstacles and occasionally looking at the digital display. There is only a small amount of research data about the efficacy of teleoperation, but it is very difficult, requiring intense concentration for missions like Embudito. At a time when the military would like to reduce manpower requirements, it is clear that teleoperated robots will not help. Furthermore, it is not clear that pure teleoperation will work as a general solution. For example, people become very 
accomplished at driving familiar terrain, but a remote human driver could easily get lost in the unfamiliar Embudito terrain.

Autonomy: For the Embudito Mission, the soldier-operator of the robot would place the robot on the ground, enable his/her display, click on each of the Observation and Target Points on the topo map, and then click Go. The automated route planner would calculate an "optimal" route, and the robot would autonomously execute the route, making route changes if required as it moved along the route.

There are gradations between the two extremes. For example, near the teleoperation end of the spectrum, the soldier-teleoperator would surely appreciate an automated route planner, or a computationally based route planning assistant. Near the autonomy end of the spectrum, an optimally planned route may make for a much more effective mission. Today there are no systematic methods to consider such gradations in order that we might prioritize the needed $R \& D$.

So what are the issues related to mission route planning? Conceptually any route can be taken from Start point to Observe point, and there are results in the research literature which optimize parameters such as energy consumption, time, or perhaps even the simple ability of the robot to traverse the route. But from the previous sections, there are many more issues which a route planner would like to take into consideration; simplistically, there are a number of $d o$ 's and don'ts which the route planner might consider, to wit:

\begin{tabular}{|ll|ll|}
\hline \multicolumn{1}{|c|}{ Don'ts } & \multicolumn{1}{c|}{ Do's } \\
\hline 1. & Don't run into obstacles & S & Do get to the Observation Point \\
\hline S & Don't spend much time in arroyos & S & Do optimize time, energy, and/or other \\
\hline S & Don't go into rock piles & S & Do communicate \\
\hline$?$ & Don't spend much time in thickets & $?$ & Do navigate \\
\hline 2. & Don't fall into holes & $?$ & Do optimize covertness \\
\hline S & Don't spend much time on ridgebacks & & \\
\hline
\end{tabular}

The table is coded: $\mathbf{W}$ means that there is a weak connection between planning done at the beginning of the mission, and the specific example of a Do or Don't. For example, there are obstacles that are smaller than the resolution of any map that is economically foreseeable, and therefore the route planner will be unable to take such obstacles into account at the beginning of the mission. $\mathbf{S}$ implies a stronger connection; for example, given information that is available such as topo maps, a reasonable estimate can be made at routes that are most energy efficient. (This is not to say that the ability to do so actually exists today.) The question marks imply that we do not yet have enough information to make a judgement about weak or strong connection. For example, it is not yet known whether there is enough information available to do the classification of vegetation areas mentioned above.

Although there is a rich history of research on automated path planning for mobile robots, it has not been tested in situations as complex as the Embudito Mission. No systematic methodology exists which deals with the pre-planning of routes - either by humans or computers - that will enable mobile robots to autonomously navigate the Embudito 
Mission, or any other except the simplest. Route planning technologies are undeveloped, perhaps even under-researched.

With all the above in mind, it seems there are several questions to be answered with respect to mission route planning:

- Will an automated route planner do better than a human route planner using the same information? How much better? Under what conditions?

- Is an "autonomous" mobile robot without a route planner conceivable? At the other extreme, will an "autonomous" mobile robot with a route planner work?

The robotics community does not have answers for these questions.

No methodology has been developed which will permit the science and technology communities to assess whether autonomy can be developed under any circumstances, or to prioritize approaches to technology development. The lack of this assessment capability presents a serious problem for the future of ground mobile robotics. Using the science and technology base that is in hand today,

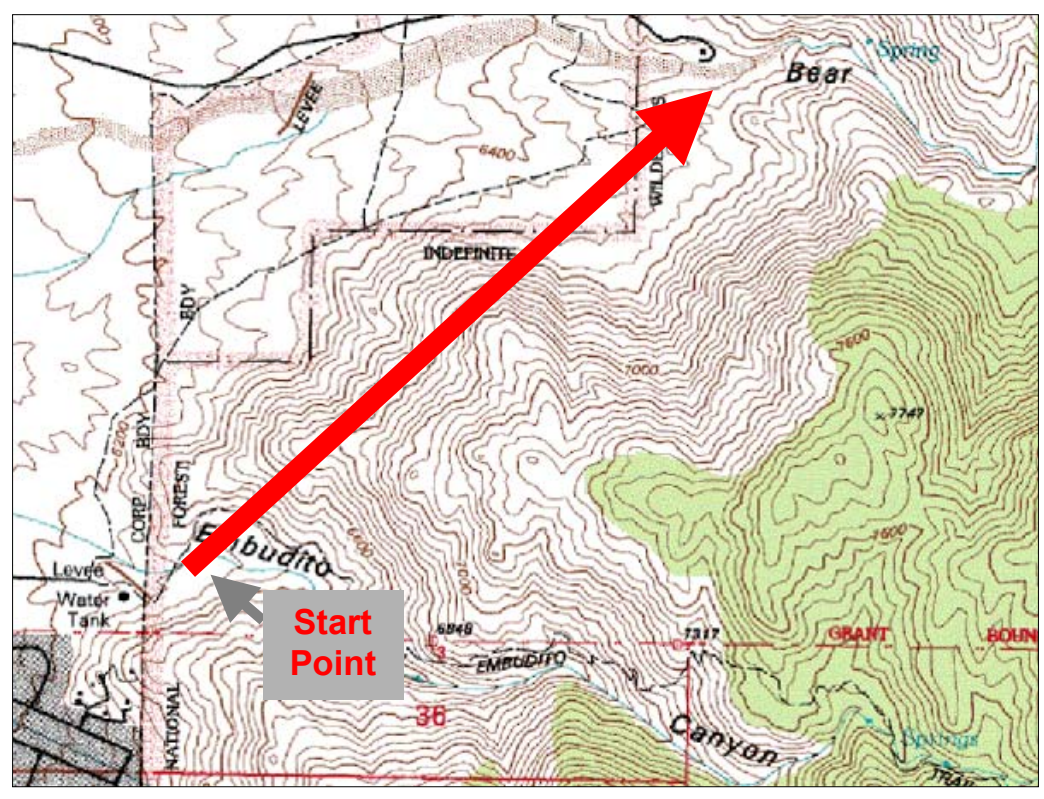
it is very easy to believe that an "autonomous" mobile robot would get lost as it attempted to go from Start point to Observation point.

\section{Robot Mobility}

To this point in this paper, the intrinsic mobility of the robot has not been prominently mentioned, primarily because it doesn't seem to be a critical issue for the Embudito Mission as long as the Rock Pile is avoided. In the back of our mind, there has been the notion of a wheeled mobile robot with a scale roughly on the order of ten cubic inches to perhaps ten cubic feet. In other words, a characteristic dimension of several inches, perhaps up to as much as several feet. Much smaller and it's not believable that the robot could hold enough energy to carry out the mission; much larger, the robots might be too large to be believable as a covert reconnaissance and surveillance system. But there are important design considerations. Bigger robots deal more easily with obstacles; consider the photo in Figure 22. In the middle to lower right, there is a tiny arroyo which is about three feet deep, and only two or three inches wide at the bottom. There are few of these in Embudito, but, if encountered, they will provide a lot of trouble for the size robots discussed above. A robot with a ChD of five feet or more might not even notice this little 
arroyo as it drove along. It however would not be as covert as a smaller robot, and might not be as "agile" as it moved in dense vegetation. There are other "gotcha's" in Embudito, such as wire fences that are not touched on in this paper, and yet must be dealt with by an autonomous mobile robot. The bottom line is that today the robotics community has no systematic way of fitting together the host of competing design considerations.

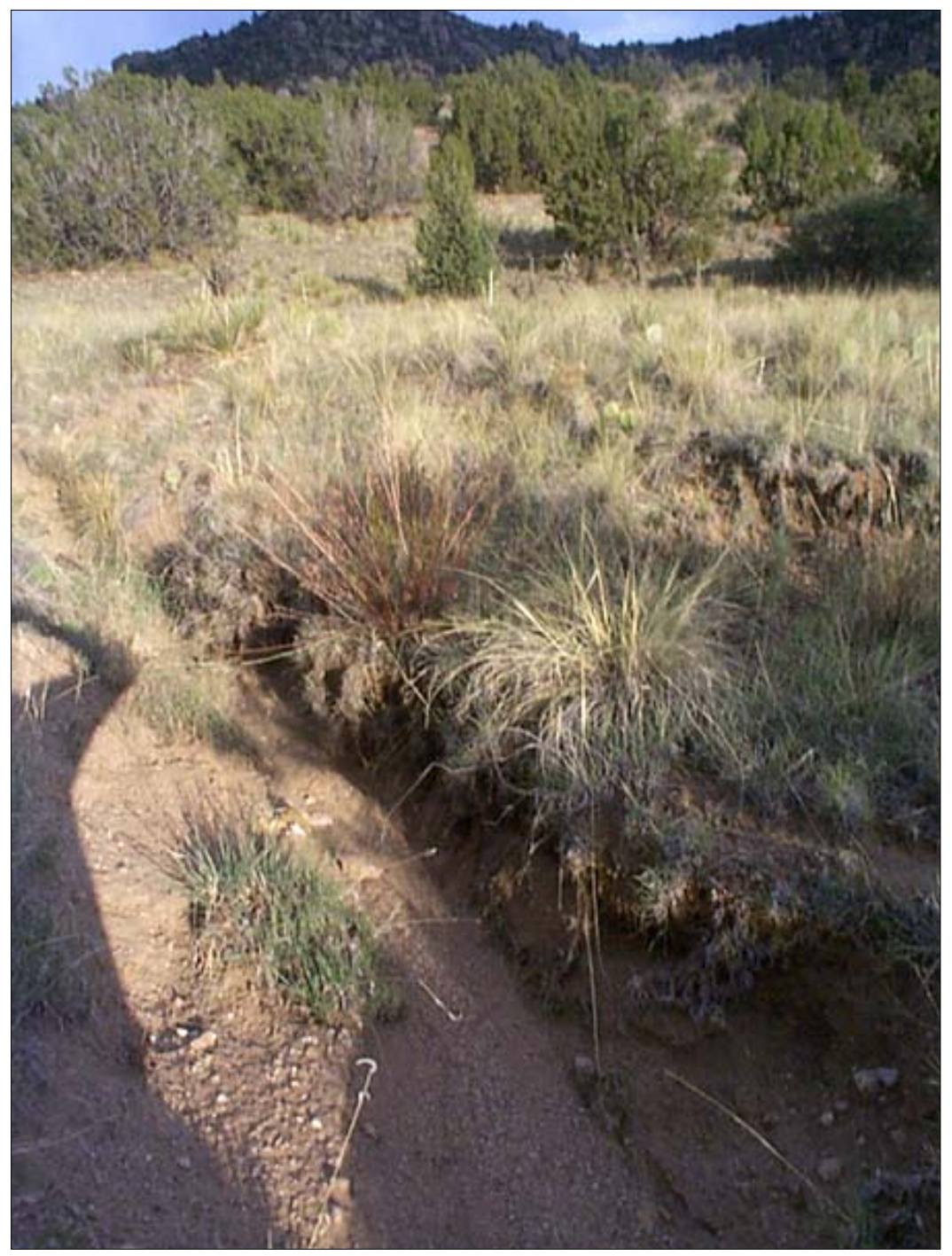

Figure 22: Small Ditch-like Arroyo

\section{The Virtual Robot and the Virtual World}

The computer models of the mobile robot, its components, its capabilities, plus the models of the environment in which the robot must carry out its mission, are referred to as the virtual robot and its virtual world (VRVW). To begin, it may be helpful to consider an analogy - the airplane simulator as in Table 1. 


\begin{tabular}{|l|l|}
\hline \multicolumn{1}{|c|}{ Virtual World } & \multicolumn{1}{c|}{ Virtual Airplane } \\
\hline $\begin{array}{l}\text { Programmable models of atmospherics; } \\
\text { e.g., wind shear, temperature, humidity, } \\
\text { etc. }\end{array}$ & $\begin{array}{l}\text { - } \begin{array}{l}\text { Programmable models of the way that } \\
\text { the airplane reacts to input from the } \\
\text { world and the pilot. }\end{array} \\
\begin{array}{l}\text { And other factors external to the } \\
\text { airplane. }\end{array}\end{array}$ \\
$\begin{array}{l}\text { There's a real pilot in the simulator of } \\
\text { course. (Aircraft designers surely use } \\
\text { computer models of the real thing.) }\end{array}$ \\
$\begin{array}{l}\text { And there is the machine that simulates } \\
\text { the motion of the aircraft. In essence, } \\
\text { its motion is a summation of everything } \\
\text { else. }\end{array}$ \\
\hline
\end{tabular}

Table 1: Airplane Simulator Analogy to VRVW

The airplane/VRVW analogy breaks down somewhat because VRVW in its purest form does not have any physical machine contained within the simulation - although some are considering "robot-in-the-loop" simulation. But to complete the analogy:

\begin{tabular}{|c|c|}
\hline Virtual World & Virtual Robot \\
\hline $\begin{array}{l}\text { - Programmable models of terrain and } \\
\text { vegetation. } \\
\text { - And other factors associated with the } \\
\text { world around the robot. }\end{array}$ & $\begin{array}{l}\text { Performance models of a robot and its } \\
\text { subsystems; i.e., the way the robot is } \\
\text { estimated to react to the world it's } \\
\text { working in. }\end{array}$ \\
\hline
\end{tabular}

Table 2: Airplane Simulator Analogy to VRVW

VRVW will:

1. Permit the robotics $S \& T$ community to develop Figure 1 in some form or fashion,

2. Enable simulation-based acquisition of robot systems,

3. Enable the design of ground mobile robot systems for specific (types of) missions,

4. Be key to successful mission route planning, and

5. Be a key component of the human to machine interface.

VRVW is important. And is conceptually straightforward. But implementation will not be so straightforward. In some cases models exist and can be adapted - mobility models exist, for example. While raw data may exist for terrain and vegetation models, no integrated thinking or plan exists - especially when the greatly differing requirements of items 1 through 5 immediately above are considered.

A well conceived, integrated approach to the Virtual Robot and Virtual World is perhaps the only way to successfully address - in an integrated way - the complexities implied by the sections above. Such a systematic approach has received too little discussion and definition. 


\section{Summary}

This paper used the so-called Embudito Mission to exemplify the issues of import to the autonomy of ground mobile robots. The paper's three core sections concluded as follows: $\sim 20$ feet and less, focusing on the various kinds of Vegetation and Obstacles which may be encountered by the robot

Today there are no systems of sensors that will enable mobile robots to negotiate the Embudito Mission. More generally, no systematic methodology exists which deals with the requirements for onboard sensing that will enable mobile robots to autonomously negotiate obstacles.

$\sim 1000$ feet and less, focusing on the differing kinds of terrain and densities of vegetation which may be encountered by the robot

There are a number of topics that must be addressed by the mobile robotics community:

- Are more and/or different levels of areal (or/volumetric) granularity needed? How many? How does one address this question in a systematic way?

- One of the reasons to be interested in lookahead sensors is to give the robot some (perhaps) less-than-detailed knowledge of what lies ahead to help it keep from getting into situations which it will have a hard time getting out of. Can lookahead sensors be efficacious; i.e., how useful would they be? Can they be made to work? What is a systematic approach for thinking about these issues?

- Would terrain and vegetation classification obviate the need for lookahead sensors? Both may be looking for features of about the same size.

Requirements at the scale of the mission itself.

Robot Navigation/Position Estimation

There is no systematic methodology that will permit analyses and tradeoffs among the various possibilities for autonomous navigation of mobile robots. For example, no general methodology exists which will permit comparison of inertial navigation systems with landmark recognition systems. Furthermore, in contrast to cruise and ballistic missiles, there is no systematic methodology for describing the requirements for navigation accuracy. Roboticists do not think of a circular error probable, although they probably should.

Mission Route Planning It seems intuitive that mission route planning would significantly enhance the chances of success of the Embudito Mission. However, no methodology for systematic and/or comparative analysis exists. Furthermore, the research literature on route planning at the scale of Embudito's complexity is sparse.

Classification of Vegetation Zones Automated classification of zones of vegetation may be very helpful to mission planning. A search is turned up no research literature on the application of classification to mobile robotics.

Robot Communication

Strategies for communication must be developed which will permit comparison of various ground relays, such as the marble, with space and airborne relays. And there is no methodology for thinking about the tradeoffs between communication 
for help and onboard replanning brains. Today there is no systematic means to consider these issues.

Robot Mobility

No systematic design and analysis methodology exists for mobile robot platforms which integrates the need for mobility with the multitude of other requirements and options.

At the highest level, no methodology has been developed which will permit the robotics R\&D community to assess whether broadly applicable autonomy can be developed, or to prioritize approaches to technology development. Such methodology is probably the province of the Virtual Robot and its Virtual World.

There is no question of the need and value of methodologies such as described above. But before embarking on their development, more "missions" need to be defined so that they can receive the same type of scrutiny as Embudito, and then contribute to the design of methodologies. At Sandia, we have begun to look at a mission that we call the Manzano High Challenge, at a locale several miles south of Embudito, which will provide additional insights. More missions should be analyzed in the same way as Embudito:

- Reconnaissance and surveillance missions in different geographical locations, and

- Different missions for ground mobile robots.

\section{Conclusion}

The following statement was made near the beginning of this paper: "there has been a very large amount of basic research funded in the last quarter century devoted to mobile robots and their supporting components." And so with only a few possible exceptions, there is research literature covering every technical topic mentioned above in this paper planning, navigation, communication, etc. Thus we do not lack a base of ideas. However, the community does not know whether any set of these ideas can be assembled to work reliably in the required set (or subset) of applications and environments. We must set out to develop Figure 1 - and a plethora of related information - if defense planners are to be able to make rational decisions about investment and deployment.

Additionally, this paper has limited itself to issues related to navigation and driving - the "get there" part of any mission. No consideration was given to the "do" part of the mission. In this case study, the mission was simple observation of remote structures. Military planners are hoping for much more; e.g., if a certain type of event occurs at the observation point, the robot should notify a commander. In other words, the robot contains the intelligence to ignore many events, and report others. If robotics is to successfully address the desires of defense planners, then systematic analysis of the "do" missions is also essential. 


\section{DISTRIBUTION: \\ 1 MS0161 Patent and Licensing Office, 11500 \\ 5 MS1002 Patrick Eicker, 15200 \\ 10 MS1004 ISRC Library, 15221 \\ 1 MS9019 Central Technical Files, 8945-1 \\ 2 MS0899 Technical Library, 9616 \\ 1 MS0612 Review \& Approval Desk, 9612 For DOE/OSTI}

